\title{
Glutathione Ethyl Ester Protects In Vitro-Maturing Bovine Oocytes against Oxidative Stress Induced by Subsequent Vitrification/Warming
}

\author{
Tania García-Martínez ${ }^{1}$, Meritxell Vendrell-Flotats ${ }^{1,2}{ }^{\circledR}$, Iris Martínez-Rodero ${ }^{1}{ }^{\circledR}$, \\ Erika Alina Ordóñez-León ${ }^{1,3}$, Manuel Álvarez-Rodríguez ${ }^{2}$, , Manel López-Béjar ${ }^{2,4}{ }^{\oplus}$, \\ Marc Yeste ${ }^{5(1)}$ and Teresa Mogas $1, *(\mathbb{D})$ \\ 1 Department of Animal Medicine and Surgery, Autonomous University of Barcelona, \\ ES-08193 Cerdanyola del Vallès, Spain; taniagarciamartinez@gmail.com (T.G.-M.); \\ meritxell.vflotats@gmail.com (M.V.-F.); iris.martinez@outlook.com (I.M.-R.); \\ alina.mvzalina@gmail.com (E.A.O.-L.) \\ 2 Department of Animal Health and Anatomy, Autonomous University of Barcelona, \\ ES-08193 Cerdanyola del Vallès, Spain; Manuel.Alvarez.Rodriguez@uab.cat (M.Á.-R.); \\ Manel.Lopez.Bejar@uab.cat (M.L.-B.) \\ 3 Grupo InVitro, Tabasco 86040, Mexico \\ 4 College of Veterinary Medicine, Western University of Health Sciences, Pomona, CA 91766, USA \\ 5 Department of Biology, Institute of Food and Agricultural Technology, University of Girona, \\ ES-17004 Girona, Spain; marc.yeste@udg.edu \\ * Correspondence: teresa.mogas@uab.cat; Tel.: +34-696-64-51-27
}

Received: 30 June 2020; Accepted: 8 October 2020; Published: 13 October 2020

\begin{abstract}
This study aimed to examine whether the addition of glutathione ethyl ester (GSH-OEt) to the in vitro maturation (IVM) medium would improve the resilience of bovine oocytes to withstand vitrification. The effects of GSH-OEt on spindle morphology, levels of reactive oxygen species (ROS), mitochondrial activity and distribution, and embryo developmental potential were assessed together with the expression of genes with a role in apoptosis (BAX, BCL2), oxidative-stress pathways (GPX1, SOD1), water channels (AQP3), implantation (IFN- $\tau$ ) and gap junctions (CX43) in oocytes and their derived blastocysts. Vitrification gave rise to abnormal spindle microtubule configurations and elevated ROS levels. Supplementation of IVM medium with GSH-OEt before vitrification preserved mitochondrial distribution pattern and diminished both cytoplasmic and mitochondrial ROS contents and percentages of embryos developing beyond the 8-cell stage were similar to those recorded in fresh non-vitrified oocytes. Although not significantly different from control vitrified oocytes, vitrified oocytes after GSH-OEt treatment gave rise to similar day 8-blastocyst and hatching rates to fresh non-vitrified oocytes. No effects of GSH-OEt supplementation were noted on the targeted gene expression of oocytes and derived blastocysts, with the exception of GPX1, AQP3 and CX43 in derived blastocysts. The addition of GSH-OEt to the IVM medium before vitrification may be beneficial for embryo development presumably as the consequence of additional anti-oxidant protection during IVM.
\end{abstract}

Keywords: cow; reactive oxygen species; cryopreservation; cryotop; spindle configuration; mitochondria; embryo development; gene expression

\section{Introduction}

The successful cryopreservation of mammalian oocytes is useful for assisted reproductive technologies including animal breeding programs and somatic cell nuclear transfer as this method 
of storage resolves the temporal and spatial limitations of oocyte supplies (for a review, see [1,2]). Vitrification has proved more efficient and reliable than slow freezing for the cryopreservation of oocytes of many species including cow [3-5], mouse [6], and human [7,8], among others. However, despite the increasing interest in this approach and its applications, yields of transferable blastocysts after the in vitro fertilization of vitrified bovine oocytes remain low [1,9].

The impaired embryo developmental potential of vitrified oocytes has been attributed to abnormal meiotic spindle assembly, destabilization of the microfilament and microtubular elements of the cytoskeleton, plasma membrane rupture, premature cortical granule exocytosis, and zona pellucida hardening, among other factors (reviewed by [1]). Moreover, vitrification severely affects the morphofunctional integrity of the oocyte's mitochondria and endogenous antioxidant systems, with the consequence of increased levels of reactive oxygen species (ROS) [10,11]. The regulation of intracellular redox potential is a crucial determinant of oocyte competence [12]. If the increased levels of ROS cannot be eliminated, ROS can cause meiotic spindle disassembly and chromosome misalignment, mitochondrial damage and ATP depletion $[13,14]$. Further, ROS can compromise the developmental capacity of embryos and promote apoptosis in oocytes and early embryos $[14,15]$ by activating the caspase cascade that executes the apoptotic program $[16,17]$.

Glutathione (GSH), a tripeptide thiol ( $\gamma$-glutamylcysteinylglycine), is the major non-enzymatic line of defense against oxidative stress owing to the reducing power of its sulfhydryl group [18]. In effect, intracellular GSH synthesis is a critical part of oocyte cytoplasm maturation and relies on the $\gamma$-glutamyl cycle during oocyte maturation. In hamster oocytes, GSH concentrations rise during germinal vesicle breakdown, peak at metaphase II and rapidly decline in zygotes and embryos at the early developmental stage [19]. Appropriate GSH reservoirs attained during in vitro maturation (IVM) are essential for the formation, maintenance and protection of the meiotic spindle against oxidative stress, the formation of the male pronucleus after fertilization [20] and further embryo development [21]. Oocytes and early embryos have a limited capacity to synthesize GSH until they develop to the blastocyst stage. Besides, extracellular GSH cannot penetrate the cell membrane or enter the oocytes/embryos before this blastocyst stage. Cumulus cells surrounding oocytes play a crucial role in intracellular GSH synthesis by absorbing thiols such as $\beta$-mercaptoethanol and cysteine through gap junctions, which are then synthesized to GSH through the $\gamma$-glutamyl cycle [22]. In fact, the addition of such thiol compounds to the IVM medium can increase intracellular GSH levels and improve the developmental potential of these oocytes in several domestic species including pigs [23] and cattle [24]. However, when cumulus cells are removed during vitrification, this limits the capacity of the oocytes to synthesize GSH, leading to a low fertilization rate and reduced developmental potential [25]. Thus, although vitrified bovine oocytes can be stimulated by IVM treatment with $\beta$-mercaptoethanol/cysteine to produce high intracellular GSH levels, this high GSH content was not found to improve a high incidence of multiple aster formation and the poor potential of fertilized oocytes to develop to the blastocyst stage [26]. This could indicate that the addition of these small thiols to the IVM medium prior to cryopreservation failed to produce sufficient amounts of GSH to overcome the negative impacts of vitrification on oocyte metabolism.

Curnow et al. [27,28] showed that $5 \mathrm{mM}$ of glutathione ethyl ester (GSH-OEt), a novel oocytepermeable, cumulus cell-independent GSH donor, is able to enhance oocyte GSH levels during maturation, improving rates of maturation, normal spindle alignment and fertilization in in vitro matured bovine and primate oocytes. GSH-OEt is a small fat-soluble molecule, which penetrates cell membranes efficiently and is hydrolyzed to GSH by intracellular esterases. It does not, therefore, rely on the $\gamma$-glutamyl cycle or require energy-dependent transport across cell membranes [29]. When added to the IVM medium, GSH-OEt has been observed to improve mitochondrial functionality and regulation of redox homeostasis in vitrified/warmed IVM murine oocytes and has been also related to a more rapid recovery of spindle birefringence and improved further embryo development [30].

The present study was thus designed to examine the efficacy of $5 \mathrm{mMGSH}-\mathrm{OEt}$ added to the in vitro maturation medium prior to vitrification/warming in terms of its capacity to reduce oxidative stress and enhance the developmental competence of vitrified bovine oocytes after their in vitro fertilization. In MII oocytes and blastocysts derived from oocytes supplemented with GSH-OEt, we also assessed the 
relative mRNA abundances of genes involved in apoptosis, oxidative-stress pathways, water channels, implantation and gap junctions.

\section{Results}

\subsection{Meiotic Spindle Status of Vitrified/Warmed Bovine Oocytes after Maturation in IVM Medium} Supplemented with GSH-OEt

Table 1 compares the effects of adding or not $5 \mathrm{mM}$ GSH-OEt to the IVM medium prior to vitrification on oocyte spindle and chromosome organization. No significant differences in percentages of metaphase II or normal spindle configuration were observed between treatments. Thus, rates of oocytes showing an abnormal microtubule configuration were similar in fresh control oocytes and VIT GSH-OEt, although no differences were observed among VIT GSH-OEt, VIT control and GSH-OEt groups. However, vitrified control oocytes showed significantly higher percentages of abnormal microtubule configurations when compared to fresh control oocytes. Detailed images of these normal and abnormal patterns are provided in Figure 1.

Table 1. Spindle configurations observed in MII bovine oocytes in vitro matured in in vitro maturation (IVM) medium with or without glutathione ethyl ester (GSH-OEt) before their vitrification.

\begin{tabular}{cccccccc}
\hline & \multirow{2}{*}{} & MII (\%) & Normal & \multicolumn{2}{c}{$\begin{array}{c}\text { Microtubule } \\
\text { Configuration (\%) }\end{array}$} & \multicolumn{2}{c}{$\begin{array}{c}\text { Chromosome } \\
\text { Distribution (\%) * }\end{array}$} \\
\cline { 5 - 8 } & & & & Abnormal & Absent & Abnormal & Absent \\
\hline Control & 127 & $79.4 \pm 9.2$ & $74.1 \pm 4.4$ & $16.2 \pm 5.6^{\mathrm{a}}$ & $9.7 \pm 1.1$ & $25.9 \pm 8.3$ & 0 \\
\hline GSH-OEt & 113 & $76.5 \pm 6.5$ & $65.6 \pm 5.7$ & $26.2 \pm 9.0^{\mathrm{ab}}$ & $8.1 \pm 4.3$ & $33.2 \pm 10.6$ & $1.1 \pm 1.1$ \\
\hline VIT Control & 71 & $60.0 \pm 5.6$ & $54.8 \pm 7.8$ & $32.7 \pm 10.8^{\mathrm{b}}$ & $12.4 \pm 1.4$ & $45.2 \pm 14.5$ & 0 \\
\hline VIT GSH-OEt & 53 & $57.4 \pm 10.7$ & $58.5 \pm 8.8$ & $31.1 \pm 9.3^{\text {ab }}$ & $10.4 \pm 5.8$ & $41.5 \pm 14$ & 0 \\
\hline
\end{tabular}

a,b Different letters indicate significant differences $(p<0.05)$. * Percentage referred to the total number of oocytes at MII. Data shown as mean \pm SEM. Treatment groups: Control, oocytes in vitro matured in IVM medium; GSH-OEt, oocytes in vitro matured in IVM medium supplemented with $5 \mathrm{mM} \mathrm{GSH-OEt;} \mathrm{VIT} \mathrm{Control,} \mathrm{oocytes} \mathrm{in} \mathrm{vitro} \mathrm{matured}$ in IVM medium and then vitrified on Cryotops followed by warming; VIT GSH-OEt, oocytes in vitro matured in IVM medium supplemented with $5 \mathrm{mM}$ of GSH-OEt and then vitrified on Cryotops followed by warming.
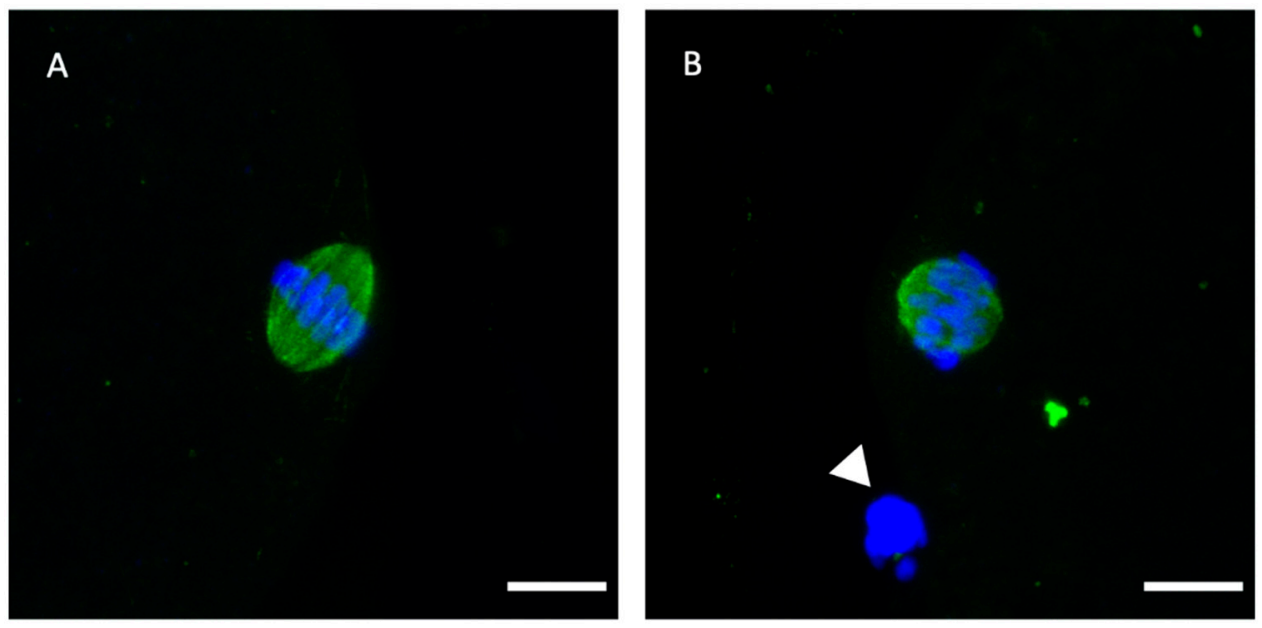

Figure 1. Cont. 

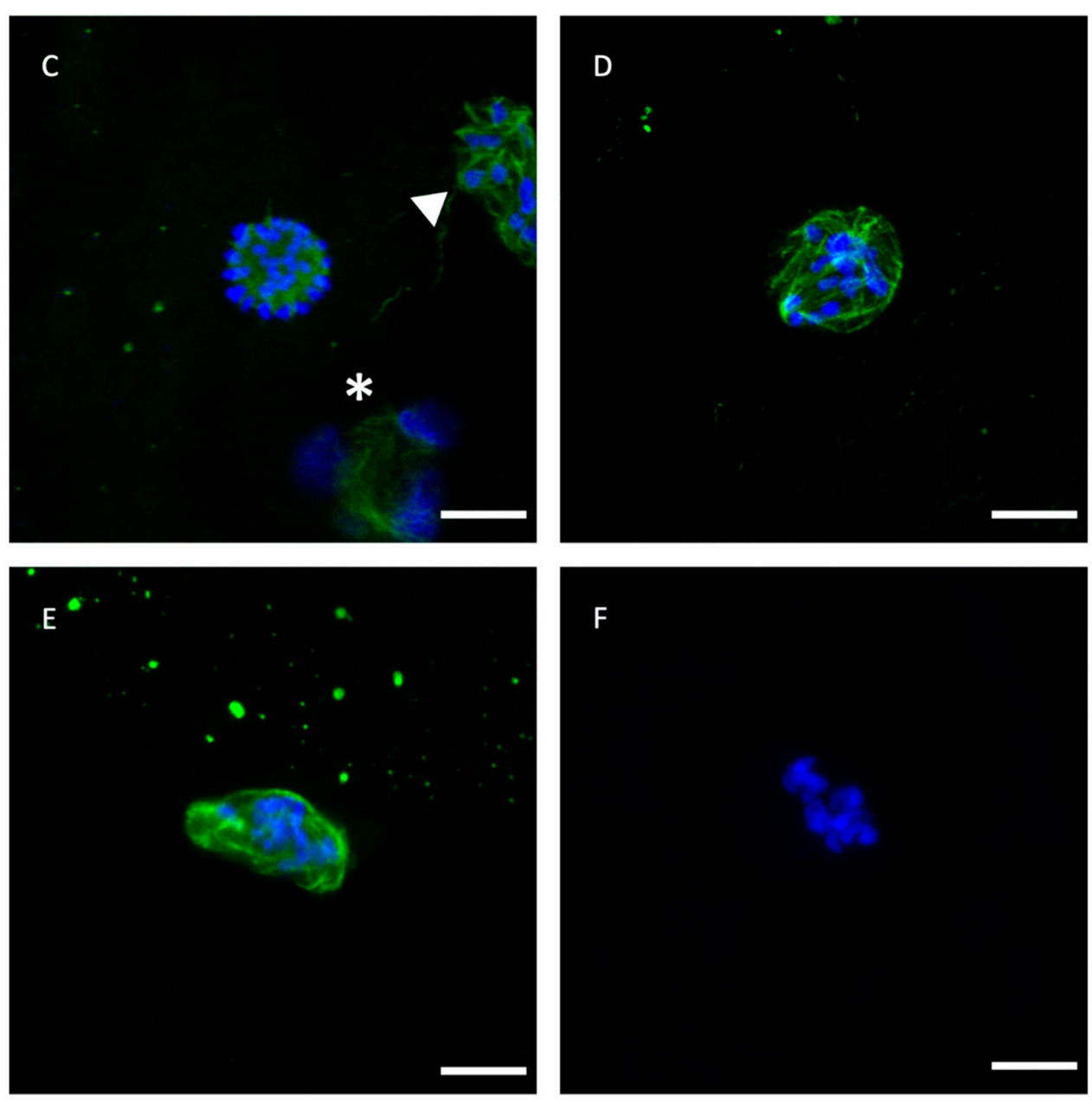

Figure 1. Representative confocal laser-scanning photomicrographs of spindle and chromosome configurations of IVM bovine oocytes after vitrification with or without GSH-OEt pretreatment. (A) Normal barrel-shaped MII spindle with microtubules forming a clear meiotic spindle with chromosomes aligned at its equator. (B,C) Abnormal spindle morphology showing partly disorganised chromosomes. (D) Abnormal spindle structure associated with a disrupted microtubule arrangement and chromosomes appearing condensed. (E) Disrupted microtubule shape. Note the decondensation of microtubules and the less condensed appearance of chromosomes. (F) Single block of condensed chromatin in the absence of microtubules. Scale bar $=10 \mu \mathrm{m}$. Green, tubulin (Alexa Fluor ${ }^{\mathrm{TM}} 488$ ); blue, chromosomes (DAPI). The white arrowhead indicates polar body and white asterisk indicates cumulus cell nuclei.

\subsection{ROS Production Detected in Vitrified/Warmed Bovine Oocytes after Their Maturation in IVM with or without GSH-OEt}

Relative ROS levels measured in MII oocytes matured with or without GSH-OEt supplementation prior to vitrification/warming are shown in Figure 2. Vitrification led to significantly higher levels of $\operatorname{ROS}(n=38 ; 14.64 \pm 1.07)(p<0.05)$ when compared to the other treatments. However, oocytes vitrified after maturation in IVM medium supplemented with $5 \mathrm{mM} \mathrm{GSH-OEt} \mathrm{(VIT} \mathrm{GSH-OEt} \mathrm{group} n=40$; $11.68 \pm 0.55)$ showed similar ROS levels to control non-vitrified oocytes matured in the absence of GSH-OEt (Control group $n=65 ; 10.30 \pm 0.18$ ). 


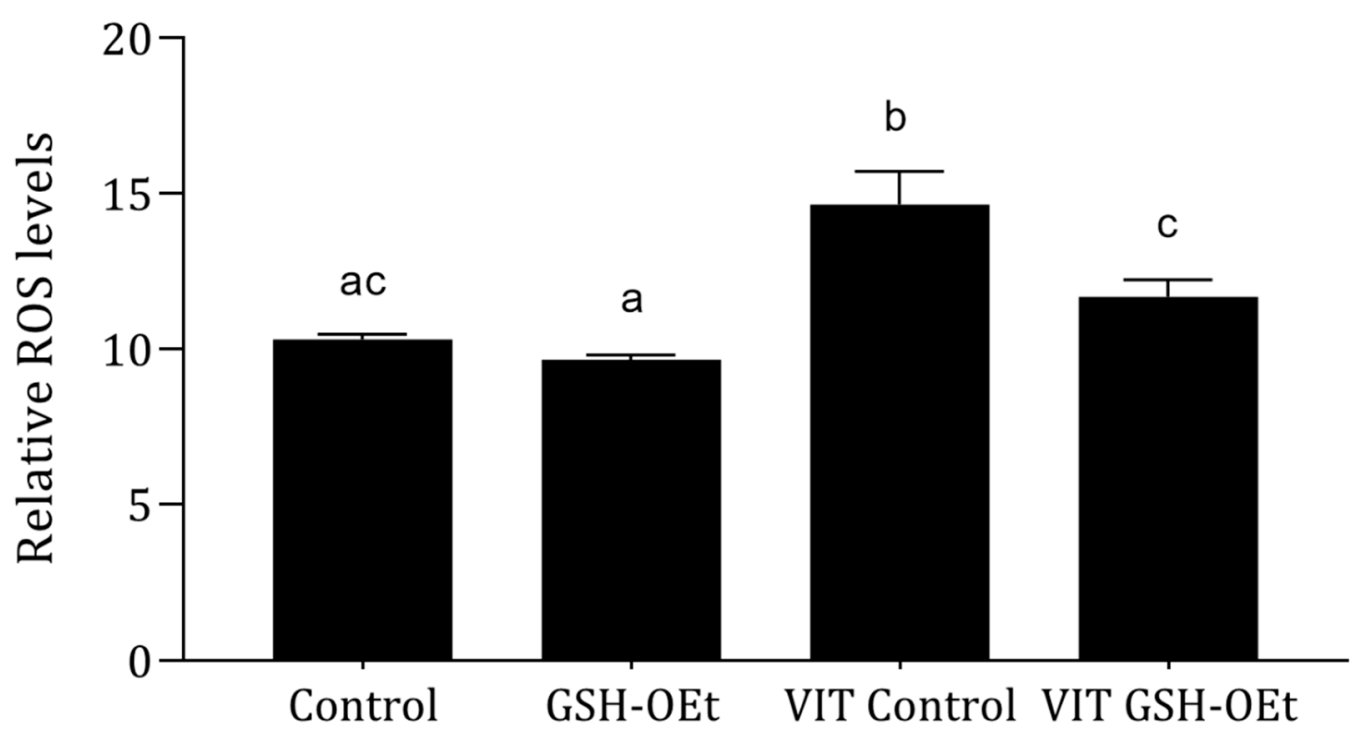

Figure 2. Effect of adding $5 \mathrm{mM}$ GSH-OEt to the IVM medium before vitrification on relative reactive oxygen species (ROS) fluorescence intensity in bovine oocytes. ${ }^{a, b, c}$ Different superscript letters within columns indicate significant differences $(p<0.05)$. Data are shown as mean \pm SEM. Treatment groups: Control, oocytes in vitro matured in IVM medium; GSH-OEt, oocytes in vitro matured in IVM medium supplemented with $5 \mathrm{mM} \mathrm{GSH-OEt;} \mathrm{VIT} \mathrm{Control,} \mathrm{oocytes} \mathrm{in} \mathrm{vitro} \mathrm{matured} \mathrm{in} \mathrm{IVM} \mathrm{medium} \mathrm{and} \mathrm{then}$ vitrified on Cryotops followed by warming; VIT GSH-OEt, oocytes in vitro matured in IVM medium supplemented with $5 \mathrm{mM}$ of GSH-OEt and then vitrified on Cryotops followed by warming.

2.3. Mitochondrial Activity and Distribution in Vitrified/Warmed Bovine Oocytes after Their Maturation in IVM Medium Supplemented with GSH-OEt

We examined the effects of GHS-OEt supplementation prior to vitrification/warming on mitochondrial distribution in MII oocytes by labelling them with a cell-permeable MitoTracker ${ }^{\circledR}$ Red $\mathrm{CM}-\mathrm{H}_{2}$ XRos. Detailed images of fluorescence labelling are shown in Figure 3A. As shown in Figure 3B, vitrification significantly increased mitochondrial oxidative activity in the MII oocytes after IVM ( $n=48,3.12 \pm 0.24)$ when compared to other treatments. While significantly lower mitochondrial oxidative activity was observed in fresh control oocytes $(n=44,1.00 \pm 0.05)$, similar mitochondrial oxidative activity was observed between non-vitrified GSH-OEt $(n=45,1.79 \pm 0.10)$ and vitrified GSH-OEt oocytes $(n=44,1.99 \pm 0.11)$.

When mitochondrial distribution was assessed (Figure 4A), a significantly higher percentage of MII oocytes showing a mitochondrial aggregate pattern was observed in the vitrified group $(n=48$, $57.40 \% \pm 7.81$ ) when compared to other treatments (Control: $n=44 ; 20.80 \% \pm 11.02$; GSG-OEt: $n=45$; $28.80 \% \pm 5.69$ and VIT GSH-OEt: $n=44 ; 34.00 \% \pm 1.84$. Figure $4 \mathrm{~B}$ shows the details of mitochondrial distribution patterns. 
A
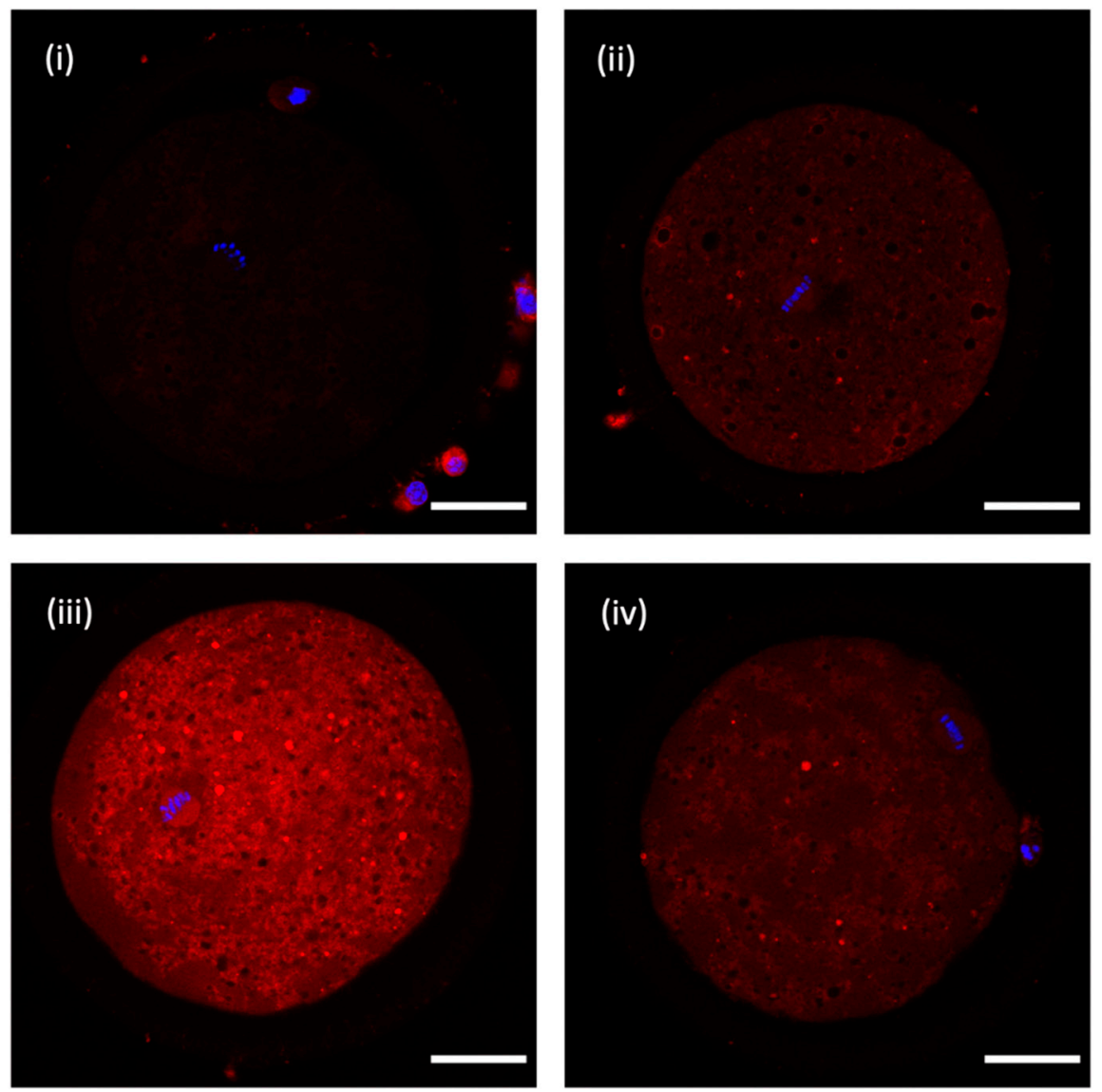

B

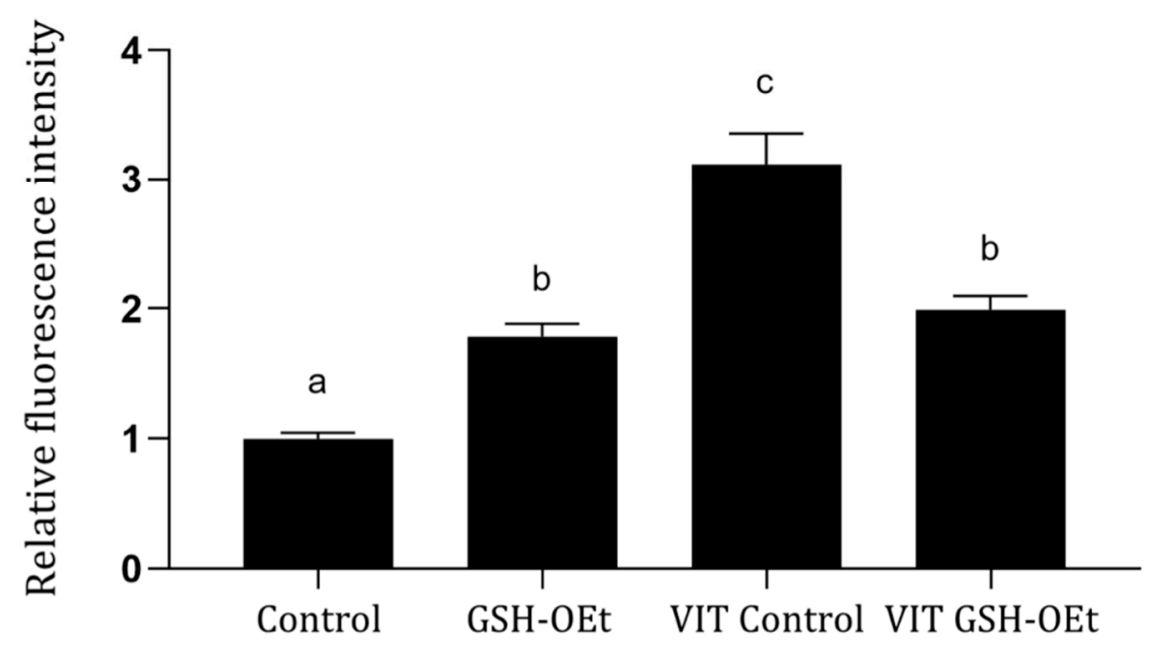

Figure 3. Effect of the addition of $5 \mathrm{mMGSH}-\mathrm{OEt}$ to the IVM medium before vitrification on mitochondrial oxidative activity in bovine oocytes. Data are shown as mean + SEM. ${ }^{a, b, c}$ Different superscripts within columns indicate significant differences $(p<0.05)$. Representative images of MII oocytes stained with MitoTracker ${ }^{\circledR}$ Red CM- $\mathrm{H}_{2}$ XRos (red) and Hoechst nuclear staining (blue): (A) (i) Control, (ii) GSH-OEt, (iii) VIT Control, (iv) VIT GSH-OEt. Scale bar $=30 \mu \mathrm{m}$. (B) Relative fluorescence intensity of mitochondrial oxidative activity in oocytes. Treatment groups: Control, oocytes in vitro matured in IVM medium; GSH-OEt, oocytes in vitro matured in IVM medium supplemented with $5 \mathrm{mM} \mathrm{GSH-OEt;} \mathrm{VIT} \mathrm{Control,}$ oocytes in vitro matured in IVM medium and then vitrified on Cryotops followed by warming; VIT GSH-OEt, oocytes in vitro matured in IVM medium supplemented with $5 \mathrm{mM}$ of GSH-OEt and then vitrified on Cryotops followed by warming. 
A

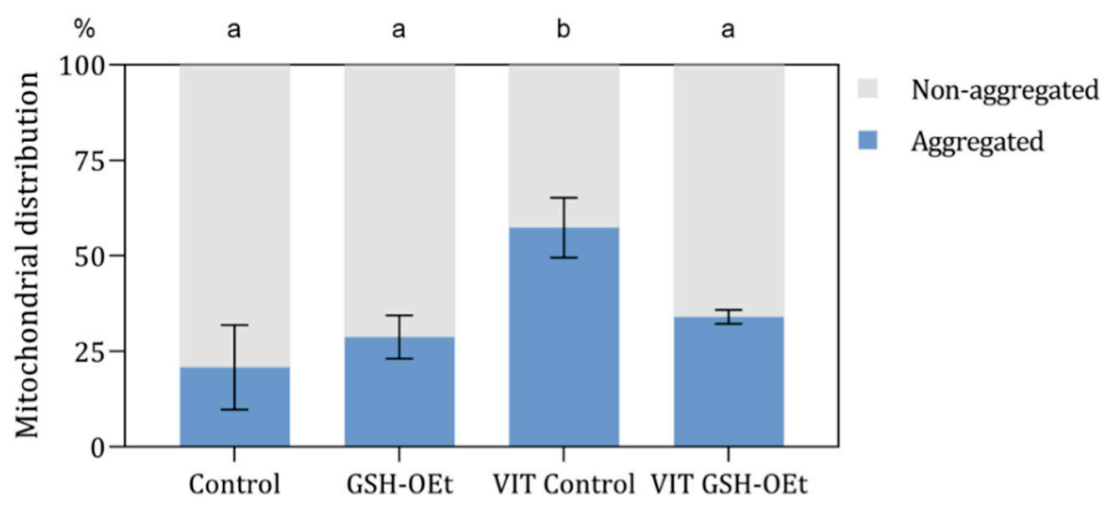

B
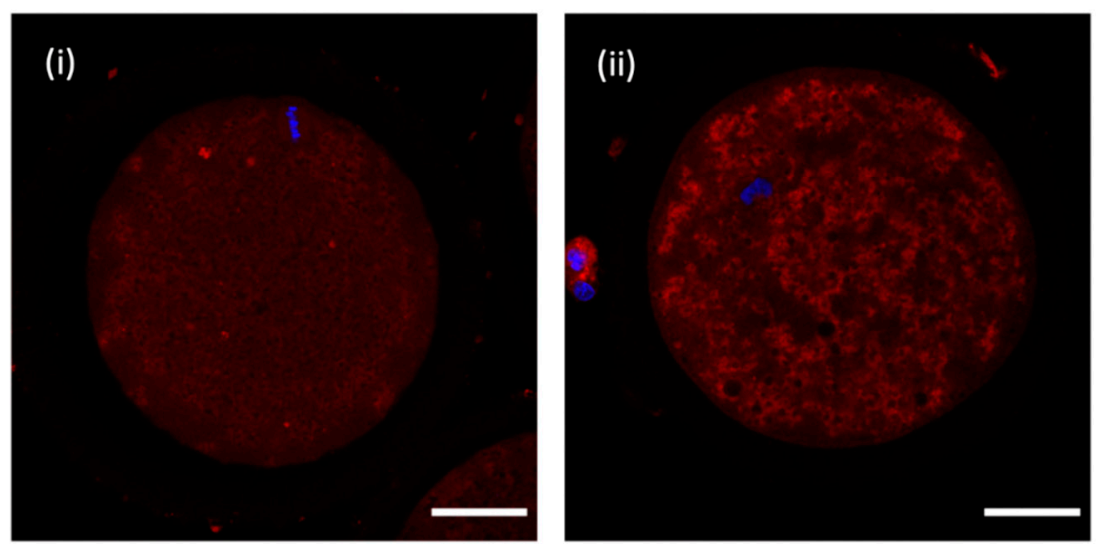

Figure 4. Effect of the addition of $5 \mathrm{mMGSH}-\mathrm{OEt}$ to the IVM medium before vitrification on mitochondrial distribution in bovine oocytes. Data are shown as mean + SEM. ${ }^{a, b}$ Different superscripts within columns indicate significant differences $(p<0.05)$. (A) Distribution of MII oocytes according to mitochondrial distribution pattern: (i) non-aggregated mitochondrial distribution; (ii) aggregated mitochondrial distribution. (B) Representative images of mitochondrial distribution with MitoTracker ${ }^{\circledR}$ Red CM- $\mathrm{H}_{2}$ XRos (red) and Hoechst nuclear staining (blue). Mitochondrial distribution was categorized according to the presence or absence of two or more aggregates in the oocyte cytoplasm into (i) non-aggregated or (ii) aggregated. Scale bar $=30 \mu \mathrm{m}$. Treatment groups: Control, oocytes in vitro matured in IVM medium; GSH-OEt, oocytes in vitro matured in IVM medium supplemented with $5 \mathrm{mM} \mathrm{GSH-OEt;} \mathrm{VIT} \mathrm{Control,}$ oocytes in vitro matured in IVM medium and then vitrified on Cryotops followed by warming; VIT GSH-OEt, oocytes in vitro matured in IVM medium supplemented with $5 \mathrm{mM}$ of GSH-OEt and then vitrified on Cryotops followed by warming.

2.4. Gene Expression in Vitrified/Warmed Bovine Oocytes after Their Maturation in IVM Medium Supplemented with GSH-OEt

Data on the relative abundances of mRNA transcripts in MII oocytes in vitro matured with GSH-OEt before vitrification/warming are provided in Figure 5. No differences were observed in relative abundances of transcripts of genes related to oxidative-stress (GPX1, SOD1), water channels (AQP3) and apoptosis (BAX, BCL2) as well as in the BAX:BCL2 ratio in MII oocytes, regardless of treatment. 
A

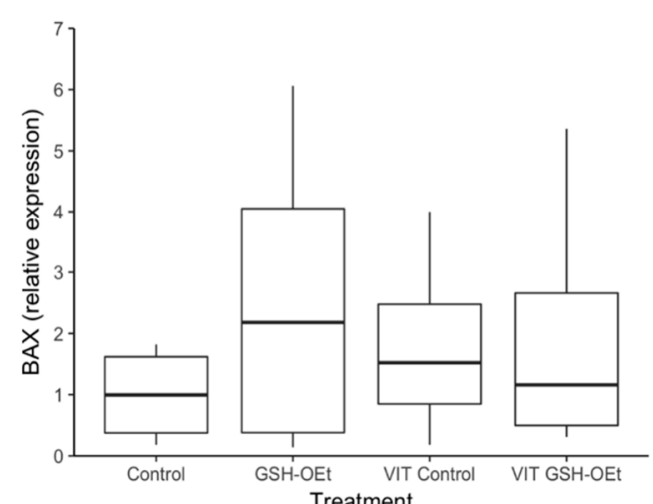

D

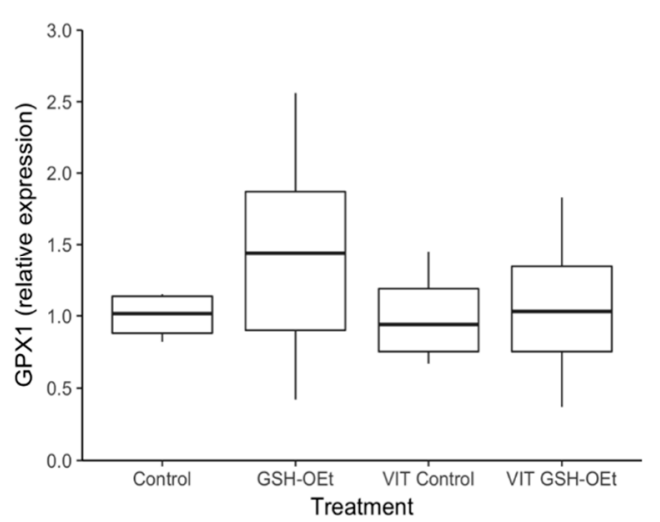

B

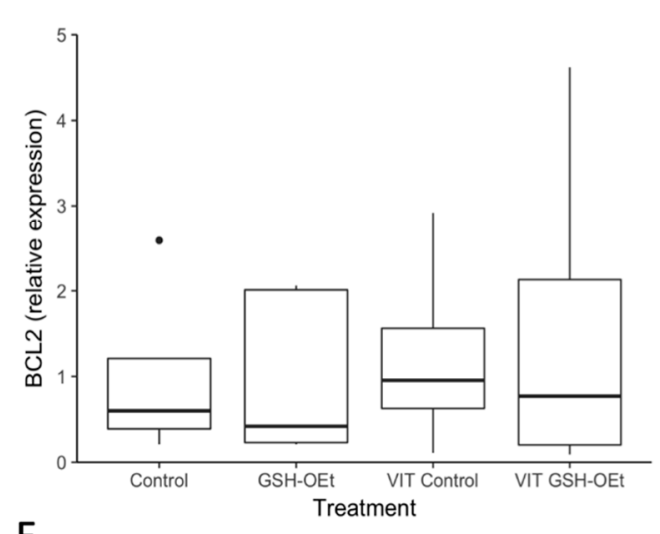

E

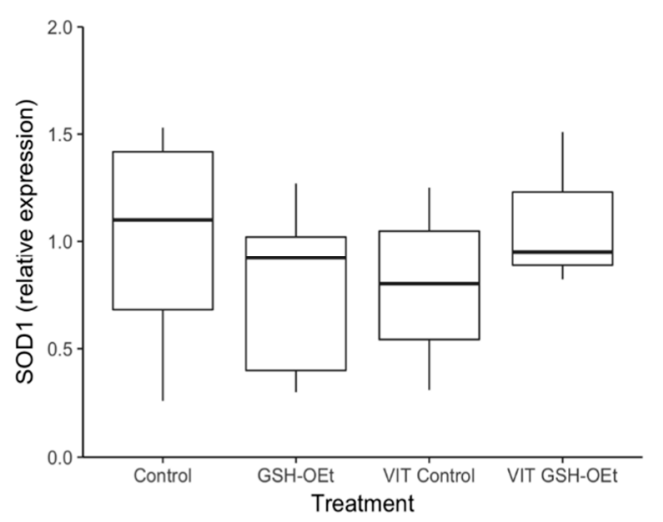

C
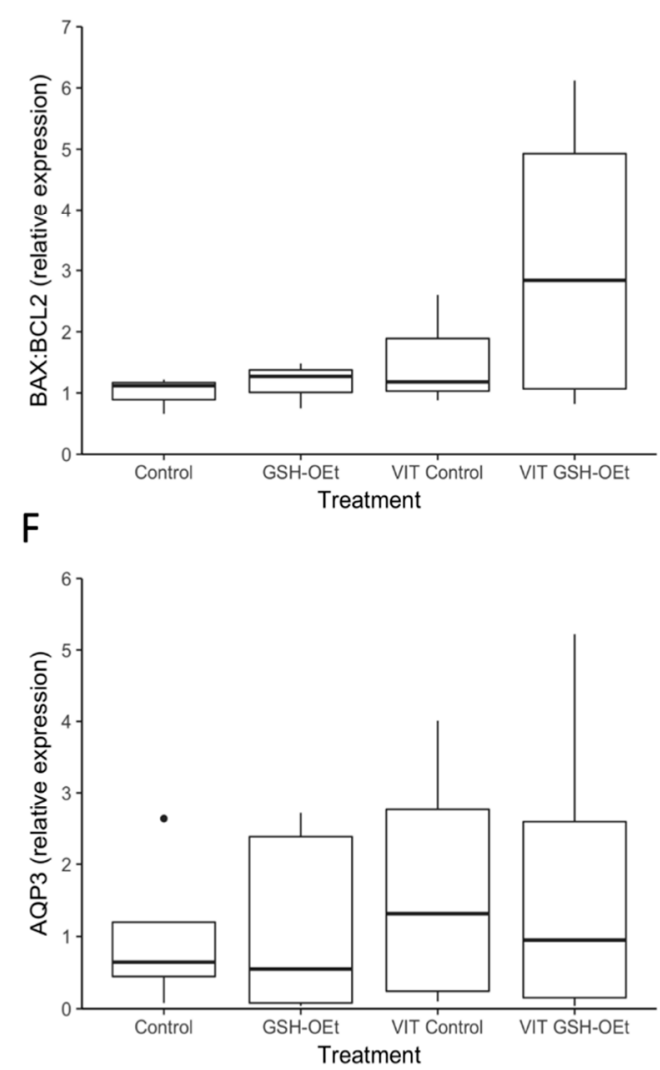

Figure 5. Box-and-whisker plot showing relative gene expression levels of (A) BAX, (B) BCL2, (C) BAX:BCL2, (D) GPX1, (E) SOD1 and (F) AQP3 in MII bovine oocytes in vitro matured in IVM medium with or without GSH-OEt before their vitrification. Box compartments represent 25 th and 75 th percentiles and whiskers represent maximum and minimum values. The line across the boxes represents the median. BAX, BCL2 associated X, apoptosis regulator; BCL2, BCL2 apoptosis regulator; GPX1, glutathione peroxidase 1; SOD1, superoxide dismutase 1; $A Q P 3$, aquaporin 3. Control, oocytes in vitro matured in IVM medium; GSH-OEt, oocytes in vitro matured in IVM medium supplemented with $5 \mathrm{mM}$ GSH-OEt; VIT Control, oocytes in vitro matured in IVM medium and then vitrified on Cryotops followed by warming; VIT GSH-OEt, oocytes in vitro matured in IVM medium supplemented with $5 \mathrm{mM}$ of GSH-OEt and then vitrified on Cryotops followed by warming. 
2.5. Developmental Competence and Gene Expression Determined in Embryos Derived from Vitrified/Warmed Bovine Oocytes In Vitro Matured in IVM Medium with or without GSH-OEt

The effects observed of GSH-OEt supplementation during in vitro maturation before vitrification/ warming on embryo development are detailed in Table 2. Matured non-vitrified oocytes gave rise to a significantly higher cleavage rate than vitrified oocytes, regardless of GSH-OEt treatment. In vitro maturation with GSH-OEt led to significantly higher D7 blastocyst rates than those recorded in both groups of vitrified oocytes but similar to values observed for non-vitrified non-GSH-OEt treated oocytes. Embryo development up to the 16-cell or blastocyst stage was lower for oocytes vitrified without prior GSH-OEt treatment compared to non-vitrified oocytes. However, oocytes vitrified after IVM with GSH-OEt yielded similar 16-cell stage and D8 blastocyst rates than non-vitrified oocytes. Likewise, while similar hatching D8-blastocyst rates were observed in the oocytes not vitrified and those vitrified after GSH-OEt treatment, D8 blastocysts derived from non-GSH-OEt-treated vitrified oocytes showed a significantly lower hatching capacity than oocytes in the non-vitrified groups.

Table 2. Developmental competence of embryos derived from bovine oocytes vitrified/warmed after their maturation in IVM medium supplemented with GSH-OEt.

\begin{tabular}{|c|c|c|c|c|c|c|c|c|c|}
\hline & \multirow{2}{*}{$n$} & \multirow{2}{*}{$\begin{array}{c}\text { Cleavage Rate } \\
48 \text { hpi }\end{array}$} & \multirow{2}{*}{$\begin{array}{l}\text { 16-Cell Embryo } \\
96 \text { hpi }\end{array}$} & \multicolumn{2}{|c|}{ Blastocyst Yields } & \multicolumn{4}{|c|}{ D8 Blastocysts } \\
\hline & & & & D7 Blastocyst & D8 Blastocyst & $\mathrm{n}_{\mathrm{D} 8}$ & Non-Expanded & Expanded & Hatched \\
\hline Control & 381 & $73.09 \pm 3.84^{\mathrm{a}}$ & $53.74 \pm 8.80^{\mathrm{a}}$ & $14.74 \pm 1.71^{\mathrm{ab}}$ & $23.12 \pm 5.17^{\mathrm{a}}$ & 85 & $48.04 \pm 14.66$ & $24.85 \pm 2.76$ & $27.11 \pm 14.70^{\mathrm{a}}$ \\
\hline GSH-OEt & 307 & $74.76 \pm 3.26^{\mathrm{a}}$ & $45.62 \pm 2.95^{\mathrm{a}}$ & $20.18 \pm 6.45^{\mathrm{a}}$ & $28.59 \pm 8.06^{\mathrm{a}}$ & 84 & $35.86 \pm 9.95$ & $41.48 \pm 5.48$ & $22.66 \pm 5.40^{a}$ \\
\hline VIT Control & 136 & $42.84 \pm 6.88^{b}$ & $25.48 \pm 4.10^{b}$ & $4.09 \pm 1.30^{b}$ & $5.26 \pm 0.58^{b}$ & 7 & $44.44 \pm 29.40$ & $55.56 \pm 29.40$ & $0^{\mathrm{b}}$ \\
\hline VIT GSH-OEt & 134 & $45.50 \pm 10.16^{b}$ & $37.54 \pm 2.44^{\mathrm{ab}}$ & $6.62 \pm 0.81^{b}$ & $13.78 \pm 3.20^{\mathrm{ab}}$ & 20 & $50.43 \pm 12.75$ & $40.04 \pm 6.71$ & $9.52 \pm 9.52 \mathrm{ab}$ \\
\hline
\end{tabular}

a,b Different letters indicate significant differences $(p<0.05)$. ${ }^{*}$ Day 7 and Day 8 blastocyst yields were calculated as proportions of the total number of oocytes inseminated at $24 \mathrm{hpi}(n)$. Data are shown as mean \pm SEM. Control, oocytes in vitro matured in IVM medium; GSH-OEt, oocytes in vitro matured in IVM medium supplemented with 5 mM GSH-OEt; VIT Control, oocytes in vitro matured in IVM medium and then vitrified on Cryotops followed by warming; VIT GSH-OEt, oocytes in vitro matured in IVM medium supplemented with $5 \mathrm{mM}$ of GSH-OEt and then vitrified on Cryotops followed by warming.

Through RT-qPCR, we obtained an overview of the expression levels of seven genes in D8-blastocysts derived from oocytes vitrified after GSH-OEt treatment (Figure 6). No significant differences in the relative abundances of genes involved in apoptosis (BAX, BCL2), oxidative-stress (SOD1) and implantation $(I F N-\tau)$ were observed in D8-blastocysts derived from fresh or vitrified/warmed oocytes, regardless of GSH-OEt treatment (Figure 6A,B,E,G, respectively). Although the abundance of GPX1 transcripts observed in blastocysts derived from vitrified oocytes previously matured with GSH-OEt did not differ from levels observed in blastocysts derived from vitrified or fresh non-treated oocytes, blastocysts in the VIT GSH-OEt group showed significantly higher levels of GPX1 transcripts compared to those in the non-vitrified GSH-OEt group (Figure 6D). Blastocysts derived from vitrified/warmed oocytes showed significantly $(p<0.05)$ higher relative AQP3-transcript abundances than blastocysts derived from fresh oocytes, regardless of GSH-OEt supplementation during in vitro maturation (Figure $6 \mathrm{~F}$ ). Expression levels of CX43 gene transcripts were significantly $(p<0.05)$ higher in D8 blastocysts arising from vitrified/warmed oocytes matured with GSH-OEt when compared to blastocysts derived from oocytes in the non-treated vitrified group or both non-vitrified groups (Figure 6H). 
A
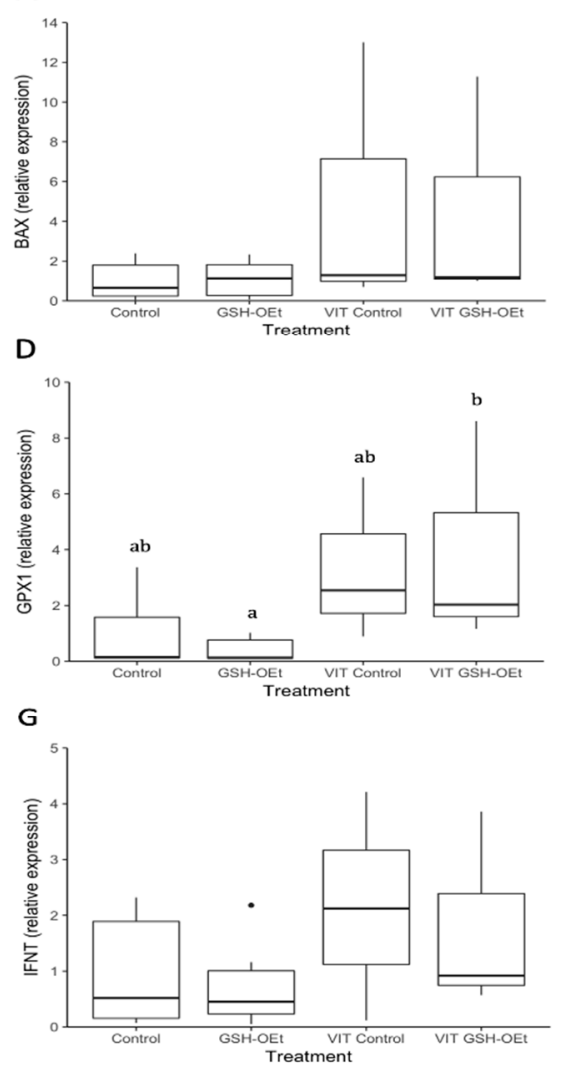
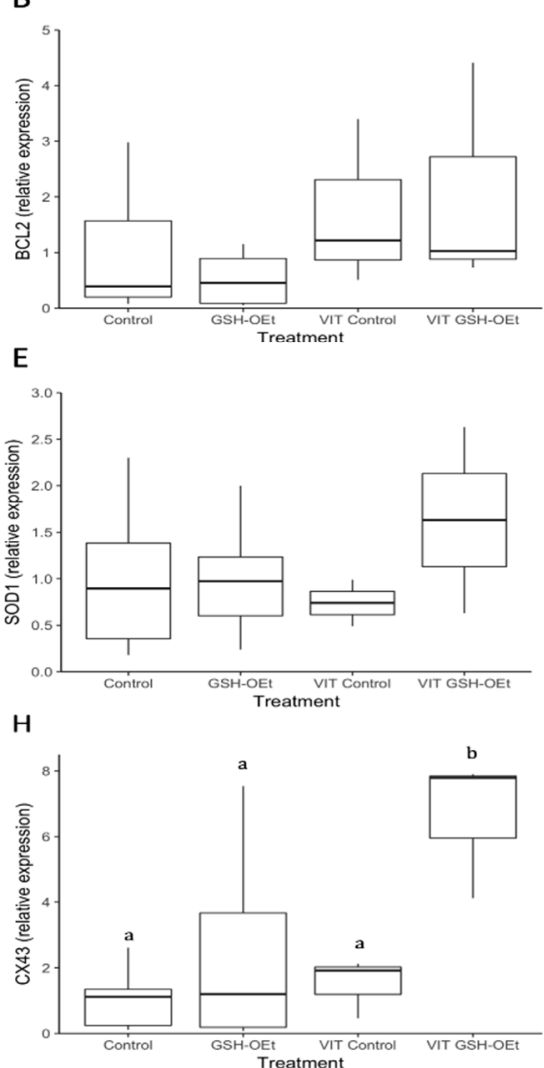

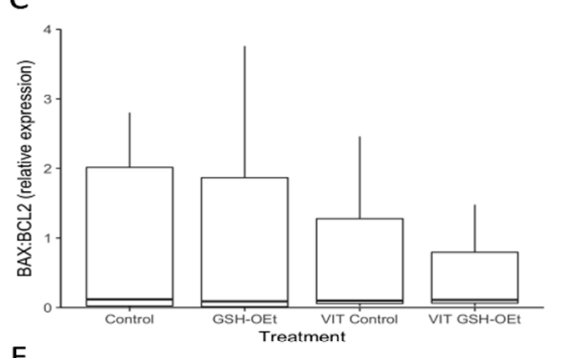

F

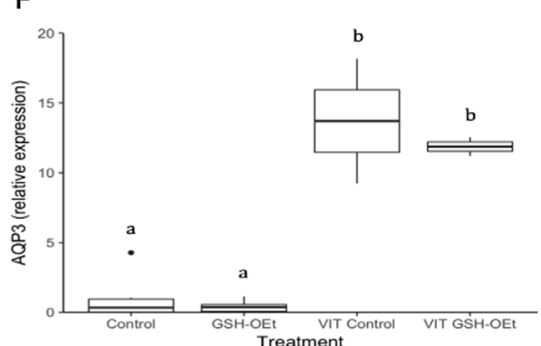

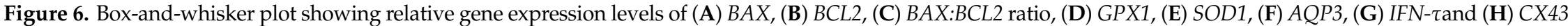
in D8 bovine blastocysts derived from oocytes in vitro matured in IVM medium with or without GSH-OEt before their vitrification. Box compartments represent 25th and 75th percentiles and whiskers represent maximum and minimum values. The line across the boxes represents the median. ${ }^{a, b}$ Different letters indicate statistically significant differences $(p<0.05)$. BAX, BCL2 associated X, apoptosis regulator; BCL2, BCL2 apoptosis regulator; GPX1, glutathione peroxidase 1; SOD1, superoxide dismutase 1; $A Q P 3$, aquaporin 3; IFN- $\tau$, interferon-tau-c2; CX43, connexin 43. Control, oocytes in vitro matured in IVM medium; GSH-OEt, oocytes in vitro matured in IVM medium supplemented with $5 \mathrm{mM}$ GSH-OEt; VIT Control, oocytes in vitro matured in IVM medium and then vitrified on Cryotops followed by warming; VIT GSH-OEt, oocytes in vitro matured in IVM medium supplemented with $5 \mathrm{mM}$ of GSH-OEt and then vitrified on Cryotops followed by warming. 


\section{Discussion}

The cryopreservation of bovine MII stage oocytes by vitrification induces heat stress and osmotic stress-causing critical damage to cellular organelles [1,9]. GSH plays an important role in maintaining a balanced intracellular redox state to protect cells against the harmful effects of oxidative stress [31]. In the present study, GSH-OEt was added as a supplement to the medium during the IVM of bovine oocytes to examine its protective role against damage induced by the vitrification/warming protocol.

The process of spindle formation and chromosome segregation is particularly sensitive to both the physical and chemical environment [32]. The correct configuration of these structures is essential in the events following oocyte fertilization such as meiosis completion, second polar body formation, pronuclei migration, and first mitotic spindle formation [33]. Disorganization of the meiotic spindles could result in chromosome dispersion, failure of normal fertilization, and end of development [34]. Increased ROS levels arising from vitrification can attack microtubules and interfere with spindle formation [13]. In compensation, increased levels of GSH support the correct assembly of microtubules by preventing ROS from attacking tubulin assembly, and maintain normal spindle function during meiosis $[35,36]$. When we examined spindle and chromosome behavior by tubulin immunofluorescence in the present study, we found no differences in percentages of normal-shaped spindles in vitrified and non-vitrified oocytes, regardless of GSH-OEt treatment. Trapphoff et al. [30] observed that oocytes vitrified after pre-incubation with GSH-OEt had normal spindles, and while abnormalities were not significantly different from those detected in fresh controls, they were significantly lower compared to abnormalities observed directly after warming in vitrified oocytes. However, irrespective of GSH-OEt supplementation, these authors noted that spindle and chromosome configurations were re-established $2 \mathrm{~h}$ after vitrification [30]. This post-warming interval of $2 \mathrm{~h}$ at $37^{\circ} \mathrm{C}$ was likely sufficient to restore spindle structure regardless of treatment, and could mask the beneficial effects of GSH-OEt pretreatment on spindle morphology. Contrarily, Li et al. [37] observed that GSH-OEt preincubation improved spindle morphology after the vitrification of in vivo matured mouse oocytes. Our study revealed that vitrification significantly increases the percentage of oocytes displaying abnormal microtubule configurations, as reported in previous studies carried out by our group [38]. However, no differences in abnormal microtubule configuration were observed in oocytes vitrified after IVM with GSH-OEt when compared to non-vitrified oocytes. We surmise the spindle may be particularly protected by GSH-OEt, as high levels of this thiol may prevent oxidation of cysteine sulphydryl-groups of the $\alpha \beta$ tubulin dimers in microtubules [35,36] and avoid the oxidation of cellular structures within mitochondria, which are affected by vitrification.

Vitrification induces damage to the endogenous antioxidant systems of oocytes, with consequent increases in ROS activity produced when metabolism resumes and cytoplasmic damage has been repaired [39]. In effect, it has been established that ROS levels rise after oocyte vitrification $[10,14,37,40]$. When ROS levels were assessed in our study, pretreatment with GSH-OEt prior to vitrification reduced ROS contents to similar levels to those of oocytes in the control non-vitrified group, while ROS levels in vitrified non-treated oocytes were significantly higher. Similarly, GSH-OEt preincubation improved mitochondrial distribution and reduced levels of intracytoplasmic ROS in vitrified mouse oocytes leading to improved embryo development and underlying the beneficial effect of GSH-OEt incubation prior to vitrification [37].

Mitochondria play a key role in adenosine triphosphate (ATP) generation for oocyte and embryonic development [41]. It is well known that mitochondria distribution is a dynamic process, and it is an important indicator of oocyte quality [42]. For example, a uniform, granulated distribution of active mitochondria in the process of oocyte maturation and also in the early embryo-specific period is essential for the normal embryo development $[43,44]$. Disruption of mitochondria has been observed in vitrified-warmed porcine [45] and bovine [14] oocytes. In the present study, we observed that vitrified oocytes displayed a higher percentage of oocytes showing a mitochondrial aggregate distribution. Damage to the cytoskeleton during vitrification might affect the movement of mitochondria within oocytes [46]. On the contrary, a significantly higher percentage of oocytes showing a homogeneous distribution of mitochondrion was observed in oocytes vitrified after IVM with GSH-OEt. This result 
reports that in vitro maturation with GSH-OEt preserve the intracellular distribution of mitochondria after vitrification. This might partially explain the observation that GSH-OEt protects against cytoskeletal injury during vitrification.

When the mitochondrial oxidative activity was assessed, similar fluorescence intensity was observed after GSH-OEt treatment in both fresh and vitrified oocytes while non-treated vitrified oocytes resulted in significantly higher activity. It has already been demonstrated that vitrification may disrupt redox status, reduce GSH content and increase both cytoplasmic and mitochondrial ROS levels, as a consequence of a higher energy requirement for the reorganization of organelles after oocyte vitrification-warming $[39,47]$. So, our results may indicate that in vitro maturation with GSH-OEt may have provided to the oocyte with the required levels of GSH to protect the vitrified oocytes from the oxidative stress induced by the vitrification/warming process.

Although no beneficial effects were observed in terms of cleavage rates, oocyte IVM with GSH-OEt prior to vitrification produced embryos that were able to overcome the 8-cell barrier and develop to the D8 blastocyst stage in similar percentages as fresh non-vitrified oocytes. Mechanisms proposed for the impacts of ROS on the developmental potential of vitrified oocytes have been mitochondrial damage, ATP depletion, apoptosis, modified calcium levels during fertilization and developmental blocks [48,49]. In our study, IVM with GSH-OEt supplementation helped the embryos to develop beyond the 8-cell block. While only $25.48 \%$ of $42.84 \%$ of cleaved embryos derived from vitrified oocytes overcame this block, $37.54 \%$ of $45.50 \%$ of cleaved embryos derived from oocytes in the VIT-GSH-OEt group reached the 16-cell stage. This proportion observed in vitrified pretreated oocytes was similar to the rates recorded in the groups of fresh non-vitrified oocytes. Similar results have been reported in mouse oocytes whereby preincubation with GSH-OEt helped vitrified mouse oocytes overcome the 2-cell block [37]. Despite the protective effect of GSH-OEt being appreciable before the 8-16 cell stage, the only mechanism explaining how GSH-OEt abolished the development block is through the degradation of ROS. Oocytes IVM with GSH-OEt prior to vitrification gave rise to similar D8 blastocyst rates and hatching abilities to non-vitrified oocytes, although both percentages were not significantly different than those observed for non-treated vitrified oocytes. Improved embryo development rates derived from vitrified oocytes after IVM with GSH-OEt have been also reported in mice [30,37]. The blastocyst rates reported in this study arising both from fresh or vitrified oocytes are lower compared to data from similar studies carried out in cattle [27,50,51]. This is likely due to our use of oocytes from cows of 12 to 18 months of age. As previously observed in our laboratory [52,53], juvenile oocytes are more sensitive to freezing injury than adult oocytes due to a failure or inability of these oocytes to undergo correct nuclear and cytoplasmic maturation [54].

ROS and mitochondria play an important role in apoptosis induction. Oxidation of mitochondrial pores by ROS due to disruption of the mitochondrial membrane potential may trigger the intrinsic apoptotic pathway [17]. BAX is a pro-apoptotic protein that leads to cell death, whereas BCL2 is an anti-apoptotic protein that promotes cell survival. The $B A X: B C L 2$ ratio determines whether a cell survives or undergoes apoptosis [55]. Several studies have examined how cryopreservation affects the expression of $B A X$ and $B C L 2$ in mammalian oocytes and embryos, but results have been inconsistent. Our study revealed no differences in transcript abundances of these two genes in oocytes and their derived embryos after vitrification, in agreement with reports in sheep [56] and mice [57]. However, vitrification has been found to up-regulate both $B A X$ and $B C L 2$ expression in bovine [58,59], porcine [60,61] and murine [37] oocytes. In a recent study, Li et al. [37] observed that BCL2 expression was lower in vitrified murine oocytes when compared to vitrified oocytes pretreated with GHS-OEt, while the $B A X$ expression level was higher in the vitrified group than in the GSH-OEt group.

To examine how supplementation of the IVM medium with $5 \mathrm{mM} \mathrm{GSH-OEt} \mathrm{affects} \mathrm{redox} \mathrm{status,}$ we analyzed two genes involved in ROS scavenging: GPX1 and SOD1. Superoxide dismutase (SOD) is located in the cytoplasm and neutralizes superoxide anions $\left(\mathrm{O}_{2}{ }^{-}\right)$by converting them to less reactive $\mathrm{H}_{2} \mathrm{O}_{2}$ which can, in turn, be scavenged by glutathione peroxidase (GPX) and catalase (CAT) reactions to form $\mathrm{H}_{2} \mathrm{O}$ and $\mathrm{O}_{2}$. The addition of GSH-OEt to the IVM medium did not affect relative expression 
levels of GPX1 and SOD1 in vitrified oocytes compared to non-vitrified oocytes. According to Yan and Harding [62], the glutathione redox cycle is the protection mechanism against low grade oxidant stress, while catalase offers more protection against severe oxidant stress. This could explain why impacts on GPX1 or SOD1 gene expression were not apparent in our vitrified oocytes. Notwithstanding, the results of studies analyzing GPX1 mRNA expression in fresh and vitrified/warmed oocytes have been inconsistent. Thus, the vitrification of porcine oocytes led to a significant increase in GPX1-transcript abundance [60], yet Sprícigo et al. [53] reported a significant decrease in GPX1 gene expression after the vitrification/warming of bovine oocytes. As in our study, Pereira et al. [60] and Turathum et al. [61] observed similar abundances of mRNA SOD1 transcripts in both fresh and vitrified oocytes. Although not significant, we observed higher GPX1 expression in D8 blastocyst derived from vitrified GSH-OEt-treated oocytes. Studies in cow oocytes have shown that relative GPX1-transcript abundance is higher in excellent/good blastocysts compared to blastocysts classified as fair, which suggests that higher GPX1 gene expression is associated with greater embryo quality [63].

Aquaporin 3 (AQP3) is a transmembrane channel protein that allows the rapid and passive movement of water as well as other tiny neutral solutes across the membrane to improve plasma membrane permeability and blastocyst cavity formation [64]. Thus, an analysis of $A Q P 3$-transcript levels in bovine blastocysts after oocyte vitrification could provide information about the permeability of the plasma membrane and the capacity for blastocyst cavity formation. Blastocysts derived from vitrified/warmed oocytes showed a significantly greater abundance of $A Q P 3$-transcripts than blastocysts derived from fresh oocytes. However, blastocysts derived from oocytes supplemented with GSH-OEt before vitrification showed a trend towards lower $A Q P 3$ expression compared to those derived from non-treated vitrified oocytes. Reduced aquaporin expression has been related to increased resistance to apoptosis [65]. Accordingly, GSH-OEt supplementation before oocyte vitrification could confer in vitro produced embryos some protection against apoptosis via $A Q P 3$ down-regulation. As no differences in $B A X$ and $B C L 2$ gene expression levels were observed between our GSH-OEt treated and non-treated blastocysts derived from vitrified oocytes, further work is needed to confirm this hypothesis.

Levels of embryonic interferon-tau-c2 (IFN- $\tau$ ) expression and secretion have been described as indicators of the developmental competence and quality of in vitro produced bovine embryos $[66,67]$. When levels of mRNA expression IFN- $\tau$ were assessed, we observed no differences in D8 blastocysts produced from fresh or vitrified/warmed in vitro matured bovine MII oocytes, regardless of prior GSH-OEt treatment. However, connexin 43 (CX43) gene transcripts were significantly upregulated in embryos derived from vitrified/warmed oocytes that had been in vitro matured in the presence of GSH-OEt. CX43 expression has been related to compaction and cell-to-cell adhesion [68]. Moreover, high CX43 expression has been related to better quality embryos and their greater cryotolerance [69].

In conclusion, the results of the present study indicate that GSH-OEt added to the IVM medium improves the cryotolerance of mature bovine oocytes to vitrification by preserving mitochondrial distribution pattern, diminishing both cytoplasmic and mitochondrial ROS levels and enhancing embryo development. No effects of GSH-OEt supplementation prior to vitrification were observed on the expression of targeted genes in oocytes and their derived blastocysts with the exception of GPX1, $A Q P 3$ and $C X 43$ in blastocysts. These data suggest that while GSH-OEt treatment is unable to fully rescue the developmental capacity of vitrified warmed oocytes, this additional antioxidant does seem to improve the resilience of bovine in vitro matured oocytes to the oxidative stress of vitrification.

\section{Materials and Methods}

\subsection{Chemicals and Suppliers}

Unless otherwise specified, all chemicals and reagents used in this study were purchased from Sigma Chemical Co (St. Louis, MO, USA). 


\subsection{Oocyte Collection and In Vitro Maturation}

The in vitro maturation (IVM), in vitro fertilization (IVF) and in vitro culture (IVC) protocols followed have been described elsewhere [70]. Briefly, ovaries from postpubertal heifers (12 to 18 months) were obtained from a local slaughterhouse and shipped to the laboratory in saline solution $(0.9 \% \mathrm{NaCl})$ at $35-37^{\circ} \mathrm{C}$. Immature cumulus-oocyte complexes (COCs) were aspirated from 3-8 mm antral follicles and washed in modified Dulbecco's PBS (PBS supplemented with $36 \mu \mathrm{g} / \mathrm{mL}$ pyruvate, $50 \mu \mathrm{g} / \mathrm{mL}$ gentamicin and $0.5 \mathrm{mg} / \mathrm{mL}$ bovine serum albumin, BSA). Only COCs with more than three compact layers of cumulus cells and a homogeneous cytoplasm were selected for IVM. Groups of up to 50 COCs were placed in $500 \mu \mathrm{L}$ of maturation medium in four-well dishes and cultured for $24 \mathrm{~h}$ at $38.5^{\circ} \mathrm{C}$ in a $5 \% \mathrm{CO}_{2}$ humidified air atmosphere. The maturation medium (IVM medium) consisted of tissue culture medium (TCM-199) supplemented with $10 \%$ (v/v) fetal bovine serum (FBS), $10 \mathrm{ng} / \mathrm{mL}$ epidermal growth factor and $50 \mu \mathrm{g} / \mathrm{mL}$ gentamicin.

\subsection{Oocyte Vitrification and Warming}

In vitro matured oocytes were vitrified/warmed as previously described by Morató et al. [38].

\subsubsection{Vitrification Protocol}

After $22 \mathrm{~h}$ of IVM, oocytes were partially denuded by gently pipetting in holding medium (HM: Hepes-TCM-199 supplemented with 20\% (v/v) FBS). Oocytes with only 2-4 layers of cumulus and corona radiata cells were transferred to HM supplemented with $7.5 \%(v / v)$ ethylene glycol (EG) and $7.5 \%(v / v)$ dimethyl sulfoxide (DMSO) for $10 \mathrm{~min}$ and then to HM supplemented with $15 \%(v / v)$ DMSO, 15\% (v/v) EG, and $0.5 \mathrm{M}$ sucrose for 45 to $60 \mathrm{~s}$. Up to five oocytes were loaded onto the Cryotop and almost all the solution was removed to leave only a thin layer covering the oocytes. Oocytes were immediately plunged into liquid nitrogen. The entire process from exposure to the vitrification solution to plunging in liquid nitrogen was completed within $90 \mathrm{~s}$.

\subsubsection{Warming Protocol}

Warming was performed by quickly immersing the tip of the Cryotop in the HM supplemented with $1 \mathrm{M}$ sucrose. After $1 \mathrm{~min}$, oocytes were transferred into HM supplemented with $0.5 \mathrm{M}$ sucrose for $3 \mathrm{~min}$ and then to $\mathrm{HM}$ for $5 \mathrm{~min}$. Oocytes were then transferred back into the maturation medium and allow to mature for 2 additional hours at $38.5^{\circ} \mathrm{C}$ in humidified air containing $5 \% \mathrm{CO}_{2}$. Vitrified/warmed oocytes were assessed for viability according to their morphology under a stereomicroscope. Only vitrified/warmed oocytes showing a normal morphology (symmetrical shape and no signs of lysis) were subjected to in vitro fertilization.

\subsection{In Vitro Fertilization and Embryo Culture}

Commercially available frozen semen from an Asturian bull (ASEAVA, Llanera, Asturias, Spain) of proven fertility was used in all experimental procedures. The content of a frozen/thawed straw was layered on top of a Bovipure density gradient $(1 \mathrm{~mL} \mathrm{40 \%} \mathrm{Bovipure} \mathrm{on} 1 \mathrm{~mL} 80 \%$ BoviPure; Nidacon Laboratories AB, Göteborg, Sweden) and centrifuged for 10 min at $300 \times g$. The underlying sperm pellet was re-suspended in $3 \mathrm{~mL}$ of BoviWash (Nidacon International, Göteborg, Sweden) and pelleted by centrifugation at $300 \times g$ for $5 \mathrm{~min}$. Spermatozoa were counted in a Neubauer chamber and diluted in an appropriate volume of fertilization medium (Tyrode's medium supplemented with $25 \mathrm{mM}$ bicarbonate, $22 \mathrm{mM}$ Na-lactate, $1 \mathrm{mM}$ Na-pyruvate, $6 \mathrm{mg} / \mathrm{mL}$ fatty acid-free BSA and $10 \mathrm{mg} / \mathrm{mL}$ heparin-sodium salt, Calbiochem, Darmstadt, Germany). Up to 50 matured oocytes were transferred to $250 \mu \mathrm{L}$ of IVF medium and co-incubated with $250 \mu \mathrm{L}$ of sperm suspension (final sperm concentration: $1 \times 10^{6}$ spermatozoa/mL) at $38.5^{\circ} \mathrm{C}$ in a $5 \% \mathrm{CO}_{2}$ humidified air atmosphere.

At the time point $18-20 \mathrm{~h}$ post-insemination (hpi), presumptive zygotes were denuded of cumulus cells by gentle pipetting and transferred to $20 \mu \mathrm{L}$ culture droplets $(1 \mathrm{embryo} / \mu \mathrm{L})$ under 
mineral oil. The culture medium was synthetic oviductal fluid (SOF) (Caisson Labs, Smithfield, VA, USA) supplemented with $0.96 \mathrm{mg} / \mathrm{mL} \mathrm{BSA}, 88.6 \mathrm{mg} / \mathrm{mL}$ Na-pyruvate, $2 \%$ non-essential amino acids, $1 \%$ essential amino acids, $0.5 \%$ gentamicin and $5 \% \mathrm{FBS}$. In vitro culture was conducted at $38.5{ }^{\circ} \mathrm{C}$ in a $5 \%$ $\mathrm{CO}_{2}, 5 \% \mathrm{O}_{2}$ and $90 \% \mathrm{~N}_{2}$ humidified atmosphere. Cleavage rates were assessed at $48 \mathrm{~h}$ post-insemination (hpi), 16-cell stage rates at 96 hpi and blastocyst yields on Days 7 (D7) and 8 (D8) post-insemination (pi). According to IETS standards, D8 embryos were classified into three groups according to the degree of blastocoel expansion: (a) non-expanded: early blastocysts (stage code 5) and blastocysts (stage code 6); (b) expanded: expanded blastocysts (stage code 7); and (c) hatched: hatching (stage code 8) or hatched blastocysts (stage code 9).

\subsection{Chromosome and Spindle Organization}

After $24 \mathrm{~h}$ of IVM, oocytes were denuded of cumulus cells by gentle pipetting and fixed in $2 \%$ $(w / v)$ paraformaldehyde-PBS for $30 \mathrm{~min}$. Oocytes were then permeabilized in Triton X-100 $(2.5 \%$ $(v / v)$ in PBS) for $20 \mathrm{~min}$, blocked in $3 \%$ BSA $(w / v)$ in PBS for $30 \mathrm{~min}$ at $38.5^{\circ} \mathrm{C}$, and immunostained for tubulin and chromatin detection as described previously by Arcarons et al. [71]. Briefly, fixed oocytes were incubated with mouse anti- $\alpha$-tubulin monoclonal antibody (Molecular Probes, Paisley, UK; 1:250 dilution) overnight at $4{ }^{\circ} \mathrm{C}$, followed by incubation with the anti-mouse IgG antibody Alexa Fluor ${ }^{\mathrm{TM}}$ 488 (Molecular Probes, Paisley, UK; 1:5000) at $38.5^{\circ} \mathrm{C}$ for $1 \mathrm{~h}$. Oocytes were washed three times in PBS at $38.5^{\circ} \mathrm{C}$ for $5 \mathrm{~min}$ after each incubation. Groups of 20 oocytes were mounted on poly L-lysine-treated coverslips fitted with a self-adhesive reinforcement ring in a $3-\mu \mathrm{L}$ drop of Vectashield containing $125 \mathrm{ng} / \mathrm{mL} 4^{\prime}, 6^{\prime}$-diamidino-2-phenylindole hydrochloride (DAPI) (Vysis Inc., Downers Grove, USA) and flattened with a coverslip. Preparations were sealed with nail varnish and stored at $4{ }^{\circ} \mathrm{C}$ protected from light until observation within the following 2 days. An epifluorescence microscope (Axioscop 40FL; Carl Zeiss, Göttingen, Germany) was used to examine tubulin (Alexa Fluor ${ }^{\mathrm{TM}} 488$; excitation $488 \mathrm{~nm}$ ) and chromatin (DAPI; excitation $405 \mathrm{~nm}$ ). The criteria used to classify chromosome and microtubule distributions have been described elsewhere [38]. In brief, a normal meiotic spindle was defined as showing the classic symmetrical barrel shape, with chromosomes aligned regularly in a compact group along the equatorial plane. In contrast, a spindle structure was recorded as abnormal when there was microtubule decondensation or partial or total disorganization, or as absent when there was a complete lack of microtubules. Chromosome organization was considered abnormal when chromosomes were dispersed or had an aberrant, less condensed appearance or lacking when chromosomes were missing.

\subsection{Reactive Oxygen Species}

Intracellular ROS levels in oocytes were quantified after IVM by labeling with $2^{\prime}, 7^{\prime}$-dichlorodihydrofluorescein diacetate $\left(\mathrm{H}_{2} \mathrm{DCFDA}\right)$ following the procedure described by Castillo-Martín et al. [72] with some modifications. In short, COCs were denuded by gentle pipetting and washed twice in PBS supplemented with $1 \mathrm{mg} / \mathrm{mL}$ of polyvinyl alcohol (PVA). Oocytes with one visible polar body were then incubated in PBS-PVA supplemented with $5 \mu \mathrm{M} \mathrm{H}_{2}$ DCFDA for $30 \mathrm{~min}$ at $38.5^{\circ} \mathrm{C}$ in a humidified $5 \% \mathrm{CO}_{2}$ air atmosphere. Oocytes were washed twice in PBS-PVA, placed on a slide and covered with a coverslip. Fluorescence emitted by the oocytes was captured under an inverted epifluorescence microscope (Zeiss Axio Vert.A1, Oberkochen, Germany) using a filter for $460-500 \mathrm{~nm}$ for excitation and 520-560 nm for emission. Fluorescence intensities were expressed in arbitrary fluorescence units (pixel) [73] using ImageJ software (Version 2.0.0-rc-69/1.52p; National Institutes of Health, Bethesda, MD, USA). Fluorescence intensities in positive control oocytes exposed to $2 \%$ hydrogen peroxide for $30 \mathrm{~min}$ at $38.5^{\circ} \mathrm{C}$ in a humidified $5 \% \mathrm{CO}_{2}$ air atmosphere were set at $100 \%$, and the relative peroxide levels of the samples calculated with respect to this value.

\subsection{Mitochondrial Activity and Distribution}

The mitochondrial membrane potential was assessed using the fluorescent probe MitoTracker ${ }^{\circledR}$ Red CM-H ${ }_{2}$ XRos $\left(\mathrm{MTR}^{\left.-\mathrm{CMH}_{2}\right)}(\mathrm{M} 7513\right.$, Molecular Probes, Invitrogen, Eugene, OR, USA) according to 
the manufacturer's instructions. MitoTracker ${ }^{\circledR}$ Red $\mathrm{CM}-\mathrm{H}_{2} \mathrm{X}$ Ros, a reduced form of X-rosamine, does not fluoresce until it enters an actively respiring cell, where it is oxidized predominantly by ROS into the fluorescent form, and is retained in mitochondria upon depolarization [74]. MII-stage oocytes were denuded from the adherence of cumulus cells and were incubated in PBS supplemented with $500 \mathrm{nM}$ dye for $30 \mathrm{~min}$ at $38.5^{\circ} \mathrm{C}$ in a dark, humidified, $5 \% \mathrm{CO}_{2}$ atmosphere. After incubation, oocytes were washed twice in PBS, fixed in a $2 \%$ PFA solution in PBS for $20 \mathrm{~min}$ at $38.5^{\circ} \mathrm{C}$ and rinsed two times in PBS. Finally, nuclei were counterstained with $0.5 \mathrm{mg} / \mathrm{mL}$ of Hoechst 33342 (Molecular Probes, Invitrogen, Eugene, OR, USA) at $38.5^{\circ} \mathrm{C}$ for $10 \mathrm{~min}$. Groups of 20 oocytes were mounted as previously described above. Oocytes were observed in their equatorial plane using a confocal microscope Leica TCS SP5 (Leica Microsystems GmbH, Mannheim, Germany) at $405 \mathrm{~nm}$ for Hoescht 33342 and $561 \mathrm{~nm}$ for MitoTracker ${ }^{\circledR}$ Red. ImageJ software (Version 2.0.0-rc-69/1.52p; National Institutes of Health, Bethesda, MD, USA) was used to quantify the fluorescence intensity of MitoTracker ${ }^{\circledR}$ Red $\mathrm{CM}-\mathrm{H}_{2} \mathrm{X}$ Ros. Fluorescence intensity of the oocytes was measured and normalized to the average in the non-vitrified control group in each experiment. In addition, the oocytes were classified according to the distribution of the mitochondria in the cytoplasm, as described previously by Moawad et al. [75] into 'aggregated' or 'non-aggregated' according to the presence or absence of two or more aggregates in the oocyte cytoplasm.

\subsection{RNA Extraction, Reverse Transcription and Quantitative Real-Time PCR Analysis}

The procedures used for RNA extraction and real-time reverse transcription-quantitative polymerase chain reaction (RT-qPCR) have been described elsewhere [50]. For gene expression analysis, groups of 30 (MII) or 5 (D8 embryos) were plunged into liquid nitrogen and stored at $-80^{\circ} \mathrm{C}$. Poly-(A)-RNA was extracted using the Dynabeads mRNA Direct Extraction Kit (Invitrogen ${ }^{\mathrm{TM}}$, Oslo, Norway) according to the manufacturer's instructions with minor modifications. For poly-(A)-RNA extraction, pooled samples were lysed in $50 \mu \mathrm{L}$ lysis buffer at room temperature for $5 \mathrm{~min}$ by gentle pipetting, and the fluid lysate was then hybridized with $10 \mathrm{~mL}$ prewashed beads, also at room temperature, for $5 \mathrm{~min}$ with gentle shaking. After hybridization, poly-(A)-RNA-bead complexes were washed at room temperature twice in $50 \mu \mathrm{L}$ Washing Buffer A and two further times in $50 \mu \mathrm{L}$ Washing Buffer B. Next, samples were eluted in $16 \mu \mathrm{L}$ elution buffer (Tris- $\mathrm{HCl}$ ) and heated to $70^{\circ} \mathrm{C}$ for $5 \mathrm{~min}$. Immediately after extraction, $4 \mu \mathrm{L} \mathrm{qScript}$ cDNAsupermix (Quanta Biosciences; Gaithersburg, MD, USA) was added and reverse transcription (RT) was performed using oligo-dT primers, random primers, dNTPs and qScript reverse transcriptase. The RT reaction was run for $5 \mathrm{~min}$ at $25^{\circ} \mathrm{C}$, followed by $1 \mathrm{~h}$ at $42^{\circ} \mathrm{C}$ to allow the RT-qPCR of mRNA, and $10 \mathrm{~min}$ at $70^{\circ} \mathrm{C}$ to denature the reverse transcriptase enzyme. After RT, the resulting CDNA was diluted in $25 \mu \mathrm{L}$ Tris- $\mathrm{HCl}$ (elution solution).

The relative abundance of mRNA transcripts was quantified by qPCR using a 7500 Real-Time PCR System (Applied Biosystems, Foster City, CA, USA). The qPCR mix contained $10 \mu \mathrm{L}$ Fast SYBR Green Master Mix (Applied Biosystems, Foster City, CA, USA), $1.2 \mu \mathrm{L}$ each primer ( $300 \mathrm{nM}$; Life Technologies, Madrid, Spain) and $2 \mu \mathrm{L}$ cDNA template. Nuclease-free water was added to make up a final volume of $20 \mu \mathrm{L}$. The PCR amplification consisted of one cycle of denaturation at $95^{\circ} \mathrm{C}$ for $10 \mathrm{~min}$, followed by 45 cycles of amplification with a denaturation step at $95{ }^{\circ} \mathrm{C}$ for $15 \mathrm{~s}$, annealing step for $1 \mathrm{~min}$ at $60{ }^{\circ} \mathrm{C}$ (the appropriate annealing temperature for the primers) and a final extension step at $72{ }^{\circ} \mathrm{C}$ for $40 \mathrm{~s}$. Fluorescence data were acquired during the final extension step. The identity of the amplified PCR products was verified by melting curve analysis and gel electrophoresis (on a $2 \%$ agarose gel containing $0.1 \mu \mathrm{g} / \mathrm{mL}$ SafeView; Applied Biological Materials, Vancouver, Canada). The melting protocol consisted of heating the samples from 50 to $95^{\circ} \mathrm{C}$ and holding at each temperature for $5 \mathrm{~s}$ while monitoring fluorescence. In each run, there were three technical replicates from each of the three biological replicates per individual gene. Negative controls for the template and for the RT were also included and amplified by PCR to ensure no cross-contamination.

Five candidate genes (BAX, BCL2, GPX1, SOD1 and $A Q P 3)$ for MII oocytes and seven genes (BAX, BCL2, GPX1, SOD1, AQP3, IFN- $\tau$ and CX43) for D8 blastocysts were used to perform quantitative 
PCR analysis in comparison with endogenous control genes (peptidylprolyl isomerase A, PPIA; and $\mathrm{H} 3$ histone, family $3 \mathrm{~A}, H 3 F 3 A)$. The comparative threshold cycle $(\triangle \Delta C \mathrm{t})$ method [76] was used to quantify relative gene expression levels and quantification was normalized to the endogenous control (housekeeping (HK) genes: PPIA and H3F3A). Fluorescence data were acquired after each elongation step to determine the threshold cycle for each sample. The threshold cycle, which is set on the log-linear phase, reflects the PCR cycle number at which the fluorescence generated within a given reaction is just above background fluorescence. Within this region of the amplification curve, a difference of one cycle is equivalent to doubling of the amplified PCR product. According to the comparative $\mathrm{Ct}$ method, the $\triangle \mathrm{Ct}$ value was determined by subtracting the mean between PPIA and H3F3A $\mathrm{Ct}$ values for each sample from the $\mathrm{Ct}$ value of each target gene of the sample for each replicate separately. Calculation of $\Delta \Delta C t$ involved the subtraction of the $\Delta C t$ value for the fresh oocyte control group from all the other $\Delta \mathrm{Ct}$ sample values. Fold differences in relative transcript abundances were calculated for target genes assuming an amplification efficiency of $100 \%$ using the formula $2^{-\Delta \Delta \mathrm{Ct}}$, or Livak and Schmittgen method [77]. Primer sequences, amplicon size and GenBank accession numbers for each gene are provided in Table 3. The efficiency of primer amplification was $100 \%$. Non-template controls were not amplified or returned a $\mathrm{Ct}$ value 10 points higher than the average $\mathrm{Ct}$ value for all genes. The experiment was repeated independently three times.

Table 3. Primer sequences used for RT-qPCR relative gene expression analysis.

\begin{tabular}{cccc}
\hline Symbol & $\begin{array}{c}\text { GenBank Accession } \\
\text { Number }\end{array}$ & Primer Sequence $\mathbf{( 5}^{\prime}-\mathbf{3}^{\prime} \mathbf{)}$ & $\begin{array}{c}\text { Fragment Size } \\
\mathbf{( b p )}\end{array}$ \\
\hline \multirow{2}{*}{ BAX } & NM_173894.1 & $\begin{array}{l}\text { F: ACCAAGAAGCTGAGCGAGTG } \\
\text { R: CGGAAAAAGACCTCTCGGGG }\end{array}$ & 116 \\
\hline \multirow{2}{*}{ GPX1 } & NM_001166486.1 & $\begin{array}{l}\text { F: GAGTTCGGAGGGGTCATGTG } \\
\text { R: TGAGCAGTGCCTTCAGAGAC }\end{array}$ & 211 \\
\hline \multirow{2}{*}{ SOD1 } & NM_174076.3 & $\begin{array}{l}\text { F: CTGAAGTACGTCCGACCAGG } \\
\text { R: GTCGGTCATGAGAGCAGTGG }\end{array}$ & 153 \\
\hline \multirow{2}{*}{ NQP3 } & NM_174615.2 & $\begin{array}{l}\text { F: ACACAAGGCTGTACCAGTGC } \\
\text { R: CACATTGCCCAGGTCTCCAA }\end{array}$ & 102 \\
\hline \multirow{2}{*}{ IFN- $\tau$} & AF238612 & $\begin{array}{l}\text { F: GTGGACCCCTACAACAACCC } \\
\text { R: CAGGAGCGGAGAGACAATGG }\end{array}$ & 222 \\
\hline \multirow{2}{*}{ CXX3 } & NM_174068.2 & $\begin{array}{l}\text { F: CTGAAGGTTCACCCAGACCC } \\
\text { R: GAGTCTGTTCATTCGGGCCA }\end{array}$ & 197 \\
\hline \multirow{2}{*}{ PPIA } & NM_178320.2 & F: AACACTCTCCAGAACACATGATCG & 294 \\
\hline H3F3A & NM_001014389.2 & F: CACGTGCTTGCCATCCAACC & 108 \\
\hline
\end{tabular}

Abbreviations: BAX, BCL2 associated X, apoptosis regulator; BCL2, BCL2 apoptosis regulator; GPX1, glutathione peroxidase 1; SOD1, superoxide dismutase $1 ; A Q P 3$, aquaporin 3; IFN- $\tau$, interferon-tau-c2; CX43, connexin 43. PPIA, peptidylprolyl isomerase $\mathrm{A}$, and $\mathrm{H} 3 \mathrm{~F} 3 \mathrm{~A}, \mathrm{H} 3$ histone, family $3 \mathrm{~A}(\mathrm{H} 3-3 \mathrm{~B})$, served as housekeeping genes.

\subsection{Experimental Design}

4.9.1. Meiotic Spindle Status, ROS Production, Mitochondrial Activity and Distribution and Gene Expression Examined in Vitrified/Warmed Bovine Oocytes after Maturation in IVM Medium with or without GSH-OEt

After collection, COCs were randomly assigned to two IVM groups: (1) Control: oocytes in vitro matured in IVM medium and (2) GSH-OEt: oocytes in vitro matured in IVM medium supplemented with $5 \mathrm{mM}$ GSH-OEt. This GSH-OEt concentration was chosen based on the findings of a previous study [27]. After $22 \mathrm{~h}$ of IVM, half of the oocytes in each IVM group were vitrified/warmed using the 
Cryotop method to give rise to the vitrification groups VIT Control and VIT GSH-OEt and allowed to recover in their respective IVM media for two additional hours. After $24 \mathrm{~h}$ of IVM, a sample of oocytes from each of the four treatment groups (Control, GSH-OEt, VIT Control and VIT GSH-OEt) was collected to assess spindle and chromosome configurations (three replicates), ROS production (three replicates) or mitochondrial oxidative activity and distribution (three replicates). For gene expression, a pool of oocytes from each group was denuded of cumulus cells by gentle pipetting and 30 oocytes showing extrusion of the first polar body were collected from each treatment group, snap-frozen in liquid nitrogen and stored at $-80^{\circ} \mathrm{C}$ until RNA extraction and RT-qPCR analysis (four replicates).

4.9.2. Developmental Competence and Gene Expression Determined in Embryos Derived from Vitrified/Warmed Bovine Oocytes In Vitro Matured in IVM Medium with or without GSH-OEt

After collection, COCs were randomly assigned to two IVM groups: (1) Control: oocytes in vitro matured in IVM medium and (2) GSH-OEt: oocytes in vitro matured in IVM medium supplemented with $5 \mathrm{mM}$ GSH-OEt. After $22 \mathrm{~h}$ of IVM, half of the oocytes in each IVM group were vitrified/warmed using the Cryotop (VIT Control and VIT GSH-OEt) and allowed to recover in their respective IVM media for two additional hours. After $24 \mathrm{~h}$ of IVM, oocytes in each of the treatment groups (Control, GSH-OEt, VIT Control and VIT GSH-OEt) were inseminated and in vitro cultured for 8 days. Cleavage rates, 16-cell stage embryos and blastocysts were assessed at 48 hpi, 96 hpi and D7 and D8 pi, respectively. In each group, D8 embryos were classified as blastocysts (stage code 6), expanded (stage code 7), or hatching/hatched (stage code 8 and 9), pooled in groups of 5, snap-frozen in liquid nitrogen and stored at $-80^{\circ} \mathrm{C}$ until RNA extraction and RT-qPCR analysis (three replicates per group).

\section{Statistical Analyses}

Data were analyzed using statistical package R, Version R 3.4.4. The normality of data distribution was checked using the Shapiro-Wilk test and homogeneity of variances through the Levene test. When required, data were linearly transformed into $\sqrt{ } \mathrm{x}, \arcsin \sqrt{ } \mathrm{x}$ or $\log (\mathrm{x})$ prior to running statistical tests. A linear mixed-effect followed by a pairwise comparison test (Tukey-adjustment) was used to assess differences between groups in spindle configuration, ROS production, mitochondrial oxidative activity and embryo development. The nonparametric Kruskal-Wallis test was used to examine the percentage in mitochondrial distribution and relative transcript abundances differences among the treatment groups. The data from the different groups were compared using the nonparametric Mann-Whitney U test. Significance was set at $p \leq 0.05$.

Author Contributions: Conceptualization, T.G.-M., M.Y. and T.M.; Formal analysis, T.G.-M. and M.Y.; Funding acquisition, M.L.-B. and T.M.; Investigation, T.G.-M., M.V.-F., I.M.-R., E.A.O.-L.; Methodology, T.G.-M., M.Á.-R., and M.Y.; Project administration, M.L.-B. and T.M.; Resources, M.L.-B., and T.M.; Supervision, M.Á.-R., M.Y. and T.M.; Validation, M.Á.-R., M.Y. and T.M.; Writing - original draft, T.G.-M.; Writing - review \& editing, M.Y. and T.M. All authors have read and agreed to the published version of the manuscript.

Funding: This study was supported by the Spanish Ministry of Science and Innovation (Project AGL2016-79802-P) and the Generalitat de Catalunya (Project No. 2017 SGR 1229). T.G.-M. was awarded an FI scholarship (2017_FI_00451) from the Generalitat de Catalunya.

Conflicts of Interest: The authors declare no conflict of interest.

\section{References}

1. Mogas, T. Update on the vitrification of bovine oocytes and invitro-produced embryos. Reprod. Fertil. Dev. 2018, 31, 105-117. [CrossRef] [PubMed]

2. Vajta, G.; Kuwayama, M. Improving cryopreservation systems. Theriogenology 2006, 65, 236-244. [CrossRef] [PubMed]

3. Chian, R.C.; Kuwayama, M.; Tan, L.; Tan, J.; Kato, O.; Nagai, T. High survival rate of bovine oocytes matured in vitro following vitrification. J. Reprod. Dev. 2004, 50, 685-696. [CrossRef] [PubMed] 
4. Vajta, G.; Holm, P.; Kuwayama, M.; Booth, P.J.; Jacobsen, H.; Greve, T.; Callesen, H. Open Pulled Straw (OPS) vitrification: A new way to reduce cryoinjuries of bovine ova and embryos. Mol. Reprod. Dev. 1998, 51, 53-58. [CrossRef]

5. Vieira, A.D.; Mezzalira, A.; Barbieri, D.P.; Lehmkuhl, R.C.; Rubin, M.I.; Vajta, G. Calves born after open pulled straw vitrification of immature bovine oocytes. Cryobiology 2002, 45, 91-94. [CrossRef]

6. Kono, T.; Kwon, O.Y.; Nakahara, T. Development of vitrified mouse oocytes after in vitro fertilization. Cryobiology 1991, 28, 50-54. [CrossRef]

7. Cao, Y.X.; Xing, Q.; Li, L.; Cong, L.; Zhang, Z.G.; Wei, Z.L.; Zhou, P. Comparison of survival and embryonic development in human oocytes cryopreserved by slow-freezing and vitrification. Fertil. Steril. 2009, 92, 1306-1311. [CrossRef]

8. Levi Setti, P.E.; Porcu, E.; Patrizio, P.; Vigiliano, V.; de Luca, R.; d'Aloja, P.; Spoletini, R.; Scaravelli, G. Human oocyte cryopreservation with slow freezing versus vitrification. Results from the National Italian Registry data, 2007-2011. Fertil. Steril. 2014, 102, 90-95.e2. [CrossRef]

9. Hwang, I.S.; Hochi, S. Recent progress in cryopreservation of bovine oocytes. BioMed Res. Int. 2014, $2014,570647$. [CrossRef]

10. Gupta, M.K.; Uhm, S.J.; Lee, H.T. Effect of vitrification and beta-mercaptoethanol on reactive oxygen species activity and in vitro development of oocytes vitrified before or after in vitro fertilization. Fertil. Steril. 2010, 93, 2602-2607. [CrossRef]

11. Zhao, X.M.; Du, W.H.; Wang, D.; Hao, H.S.; Liu, Y.; Qin, T.; Zhu, H.B. Recovery of mitochondrial function and endogenous antioxidant systems in vitrified bovine oocytes during extended in vitro culture. Mol. Reprod. Dev. 2011, 78, 942-950. [CrossRef] [PubMed]

12. Dumollard, R.; Ward, Z.; Carroll, J.; Duchen, M.R. Regulation of redox metabolism in the mouse oocyte and embryo. Development 2007, 134, 455-465. [CrossRef] [PubMed]

13. Choi, W.J.; Banerjee, J.; Falcone, T.; Bena, J.; Agarwal, A.; Sharma, R.K. Oxidative stress and tumor necrosis factor-alpha-induced alterations in metaphase II mouse oocyte spindle structure. Fertil. Steril. 2007, 88 (Suppl. 4), 1220-1231. [CrossRef] [PubMed]

14. Liang, S.; Yuan, B.; Kwon, J.W.; Ahn, M.; Cui, X.S.; Bang, J.K.; Kim, N.H. Effect of antifreeze glycoprotein 8 supplementation during vitrification on the developmental competence of bovine oocytes. Theriogenology 2016, 86, 485-494 e1. [CrossRef] [PubMed]

15. Sprícigo, J.; Morato, R.; Arcarons, N.; Yeste, M.; Dode, M.A.; López-Bejar, M.; Mogas, T. L-Carnitine and/or Resveratrol supplementation during the in vitro maturation of bovine oocytes prior to their vitrification and warming: Effects on spindle morphology, apoptosis, molecular profile and embryo development. Mol. Reprod. Dev. 2016. under revision.

16. Suen, D.F.; Norris, K.L.; Youle, R.J. Mitochondrial dynamics and apoptosis. Genes Dev. 2008, 22, 1577-1590. [CrossRef]

17. Simon, H.U.; Haj-Yehia, A.; Levi-Schaffer, F. Role of reactive oxygen species (ROS) in apoptosis induction. Apoptosis 2000, 5, 415-418. [CrossRef]

18. Meister, A.; Anderson, M.E. Glutathione. Annu. Rev. Biochem. 1983, 52, 711-760. [CrossRef]

19. Zuelke, K.A.; Jeffay, S.C.; Zucker, R.M.; Perreault, S.D. Glutathione (GSH) concentrations vary with the cell cycle in maturing hamster oocytes, zygotes, and pre-implantation stage embryos. Mol. Reprod. Dev. 2003, 64, 106-112. [CrossRef]

20. Sutovsky, P.; Schatten, G. Depletion of glutathione during bovine oocyte maturation reversibly blocks the decondensation of the male pronucleus and pronuclear apposition during fertilization. Biol. Reprod. 1997, 56, 1503-1512. [CrossRef]

21. de Matos, D.G.; Furnus, C.C. The importance of having high glutathione (GSH) level after bovine in vitro maturation on embryo development effect of beta-mercaptoethanol, cysteine and cystine. Theriogenology 2000, 53, 761-771. [CrossRef]

22. Luberda, Z. The role of glutathione in mammalian gametes. Reprod. Biol. 2005, 5, 5-17. [PubMed]

23. Abeydeera, L.R.; Wang, W.H.; Cantley, T.C.; Prather, R.S.; Day, B.N. Presence of beta-mercaptoethanol can increase the glutathione content of pig oocytes matured in vitro and the rate of blastocyst development after in vitro fertilization. Theriogenology 1998, 50, 747-756. [CrossRef] 
24. de Matos, D.G.; Furnus, C.C.; Moses, D.F.; Martinez, A.G.; Matkovic, M. Stimulation of glutathione synthesis of in vitro matured bovine oocytes and its effect on embryo development and freezability. Mol. Reprod. Dev. 1996, 45, 451-457. [CrossRef]

25. de Matos, D.G.; Furnus, C.C.; Moses, D.F. Glutathione synthesis during in vitro maturation of bovine oocytes: Role of cumulus cells. Biol. Reprod. 1997, 57, 1420-1425. [CrossRef]

26. Hara, H.; Yamane, I.; Noto, I.; Kagawa, N.; Kuwayama, M.; Hirabayashi, M.; Hochi, S. Microtubule assembly and in vitro development of bovine oocytes with increased intracellular glutathione level prior to vitrification and in vitro fertilization. Zygote 2014, 22, 476-482. [CrossRef] [PubMed]

27. Curnow, E.C.; Ryan, J.P.; Saunders, D.M.; Hayes, E.S. Developmental potential of bovine oocytes following IVM in the presence of glutathione ethyl ester. Reprod. Fertil. Dev. 2010, 22, 597-605. [CrossRef]

28. Curnow, E.C.; Ryan, J.P.; Saunders, D.M.; Hayes, E.S. Primate model of metaphase I oocyte in vitro maturation and the effects of a novel glutathione donor on maturation, fertilization, and blastocyst development. Fertil. Steril. 2011, 95, 1235-1240. [CrossRef]

29. Meister, A. Methods for the selective modification of glutathione metabolism and study of glutathione transport. Methods Enzym. 1985, 113, 571-585.

30. Trapphoff, T.; Heiligentag, M.; Simon, J.; Staubach, N.; Seidel, T.; Otte, K.; Frohlich, T.; Arnold, G.J.; Eichenlaub-Ritter, U. Improved cryotolerance and developmental potential of in vitro and in vivo matured mouse oocytes by supplementing with a glutathione donor prior to vitrification. Mol. Hum. Reprod. 2016, $22,867-881$.

31. Takahashi, M. Oxidative stress and redox regulation on in vitro development of mammalian embryos. J. Reprod. Dev. 2012, 58, 1-9. [CrossRef] [PubMed]

32. Sanfins, A.; Lee, G.Y.; Plancha, C.E.; Overstrom, E.W.; Albertini, D.F. Distinctions in meiotic spindle structure and assembly during in vitro and in vivo maturation of mouse oocytes. Biol. Reprod. 2003, 69, 2059-2067. [CrossRef] [PubMed]

33. Schatten, G.; Simerly, C.; Schatten, H. Microtubule configurations during fertilization, mitosis, and early development in the mouse and the requirement for egg microtubule-mediated motility during mammalian fertilization. Proc. Natl. Acad. Sci. USA 1985, 82, 4152-4156. [CrossRef] [PubMed]

34. Eroglu, A.; Toth, T.L.; Toner, M. Alterations of the cytoskeleton and polyploidy induced by cryopreservation of metaphase II mouse oocytes. Fertil. Steril. 1998, 69, 944-957. [CrossRef]

35. Oliver, J.M.; Albertini, D.F.; Berlin, R.D. Effects of glutathione-oxidizing agents on microtubule assembly and microtubule-dependent surface properties of human neutrophils. J. Cell Biol. 1976, 71, 921-932. [CrossRef] [PubMed]

36. Zuelke, K.A.; Jones, D.P.; Perreault, S.D. Glutathione oxidation is associated with altered microtubule function and disrupted fertilization in mature hamster oocytes. Biol. Reprod. 1997, 57, 1413-1419. [CrossRef]

37. Li, Z.; Gu, R.; Lu, X.; Zhao, S.; Feng, Y.; Sun, Y. Preincubation with glutathione ethyl ester improves the developmental competence of vitrified mouse oocytes. J. Assist. Reprod. Genet. 2018, 35, 1169-1178. [CrossRef]

38. Morato, R.; Izquierdo, D.; Paramio, M.T.; Mogas, T. Cryotops versus open-pulled straws (OPS) as carriers for the cryopreservation of bovine oocytes: Effects on spindle and chromosome configuration and embryo development. Cryobiology 2008, 57, 137-141. [CrossRef]

39. Succu, S.; Gadau, S.D.; Serra, E.; Zinellu, A.; Carru, C.; Porcu, C.; Naitana, S.; Berlinguer, F.; Leoni, G.G. A recovery time after warming restores mitochondrial function and improves developmental competence of vitrified ovine oocytes. Theriogenology 2018, 110, 18-26. [CrossRef]

40. Somfai, T.; Ozawa, M.; Noguchi, J.; Kaneko, H.; Kuriani Karja, N.W.; Farhudin, M.; Dinnyes, A.; Nagai, T.; Kikuchi, K. Developmental competence of in vitro-fertilized porcine oocytes after in vitro maturation and solid surface vitrification: Effect of cryopreservation on oocyte antioxidative system and cell cycle stage. Cryobiology 2007, 55, 115-126. [CrossRef]

41. Dadarwal, D.; Adams, G.P.; Hyttel, P.; Brogliatti, G.M.; Caldwell, S.; Singh, J. Organelle reorganization in bovine oocytes during dominant follicle growth and regression. Reprod Biol Endocrinol 2015, 13, 124. [CrossRef] [PubMed]

42. Hoshino, Y. Updating the markers for oocyte quality evaluation: Intracellular temperature as a new index. Reprod Med. Biol. 2018, 17, 434-441. [CrossRef] [PubMed] 
43. Nagai, S.; Mabuchi, T.; Hirata, S.; Shoda, T.; Kasai, T.; Yokota, S.; Shitara, H.; Yonekawa, H.; Hoshi, K. Correlation of abnormal mitochondrial distribution in mouse oocytes with reduced developmental competence. Tohoku J. Exp. Med. 2006, 210, 137-144. [CrossRef]

44. Brevini, T.A.; Cillo, F.; Antonini, S.; Gandolfi, F. Cytoplasmic remodelling and the acquisition of developmental competence in pig oocytes. Anim. Reprod. Sci. 2007, 98, 23-38. [CrossRef]

45. Dai, J.; Wu, C.; Muneri, C.W.; Niu, Y.; Zhang, S.; Rui, R.; Zhang, D. Changes in mitochondrial function in porcine vitrified MII-stage oocytes and their impacts on apoptosis and developmental ability. Cryobiology 2015, 71, 291-298. [CrossRef]

46. Morato, R.; Mogas, T.; Maddox-Hyttel, P. Ultrastructure of bovine oocytes exposed to Taxol prior to OPS vitrification. Mol. Reprod. Dev. 2008, 75, 1318-1326. [CrossRef] [PubMed]

47. Castillo-Martin, M.; Bonet, S.; Morato, R.; Yeste, M. Supplementing culture and vitrification-warming media with l-ascorbic acid enhances survival rates and redox status of IVP porcine blastocysts via induction of GPX1 and SOD1 expression. Cryobiology 2014, 68, 451-458. [CrossRef]

48. Favetta, L.A.; St John, E.J.; King, W.A.; Betts, D.H. High levels of p66shc and intracellular ROS in permanently arrested early embryos. Free Radic. Biol. Med. 2007, 42, 1201-1210. [CrossRef]

49. Yoneda, A.; Suzuki, K.; Mori, T.; Ueda, J.; Watanabe, T. Effects of delipidation and oxygen concentration on in vitro development of porcine embryos. J. Reprod. Dev. 2004, 50, 287-295. [CrossRef]

50. Arcarons, N.; Vendrell-Flotats, M.; Yeste, M.; Mercade, E.; Lopez-Bejar, M.; Mogas, T. Cryoprotectant role of exopolysaccharide of Pseudomonas sp. ID1 in the vitrification of IVM cow oocytes. Reprod. Fertil. Dev. 2019, 31, 1507-1519. [CrossRef]

51. Barros, F.D.A.; Adona, P.R.; Guemra, S.; Damiao, B.C.M. Oxidative homeostasis in oocyte competence for in vitro embryo development. Anim. Sci. J. 2019, 90, 1343-1349. [CrossRef] [PubMed]

52. Albarracin, J.L.; Morato, R.; Izquierdo, D.; Mogas, T. Vitrification of calf oocytes: Effects of maturation stage and prematuration treatment on the nuclear and cytoskeletal components of oocytes and their subsequent development. Mol. Reprod. Dev. 2005, 72, 239-249. [CrossRef] [PubMed]

53. Spricigo, J.F.; Morato, R.; Arcarons, N.; Yeste, M.; Dode, M.A.; Lopez-Bejar, M.; Mogas, T. Assessment of the effect of adding L-carnitine and/or resveratrol to maturation medium before vitrification on in vitro-matured calf oocytes. Theriogenology 2017, 89, 47-57. [CrossRef]

54. Khatir, H.; Carolan, C.; Lonergan, P.; Mermillod, P. Characterization of calf follicular fluid and its ability to support cytoplasmic maturation of cow and calf oocytes. J. Reprod. Fertil. 1997, 111, 267-275. [CrossRef] [PubMed]

55. Renault, T.T.; Dejean, L.M.; Manon, S. A brewing understanding of the regulation of Bax function by Bcl-xL and Bcl-2. Mech. Ageing Dev. 2017, 161 (Pt B), 201-210. [CrossRef]

56. Ebrahimi, B.; Valojerdi, M.R.; Eftekhari-Yazdi, P.; Baharvand, H. In vitro maturation, apoptotic gene expression and incidence of numerical chromosomal abnormalities following cryotop vitrification of sheep cumulus-oocyte complexes. J. Assist. Reprod Genet. 2010, 27, 239-246. [CrossRef] [PubMed]

57. Dhali, A.; Anchamparuthy, V.M.; Butler, S.P.; Pearson, R.E.; Mullarky, I.K.; Gwazdauskas, F.C. Effect of droplet vitrification on development competence, actin cytoskeletal integrity and gene expression in in vitro cultured mouse embryos. Theriogenology 2009, 71, 1408-1416. [CrossRef]

58. Kuzmany, A.; Havlicek, V.; Wrenzycki, C.; Wilkening, S.; Brem, G.; Besenfelder, U. Expression of mRNA, before and after freezing, in bovine blastocysts cultured under different conditions. Theriogenology 2011, 75, 482-494. [CrossRef]

59. Madrid Gaviria, S.; Lopez Herrera, A.; Urrego, R.; Restrepo Betancur, G.; Echeverri Zuluaga, J.J. Effect of resveratrol on vitrified in vitro produced bovine embryos: Recovering the initial quality. Cryobiology 2019, 89, 42-50. [CrossRef]

60. Pereira, B.A.; Zangeronimo, M.G.; Castillo-Martin, M.; Gadani, B.; Chaves, B.R.; Rodriguez-Gil, J.E.; Bonet, S.; Yeste, M. Supplementing Maturation Medium With Insulin Growth Factor I and Vitrification-Warming Solutions With Reduced Glutathione Enhances Survival Rates and Development Ability of in vitro Matured Vitrified-Warmed Pig Oocytes. Front. Physiol. 2018, 9, 1894. [CrossRef]

61. Turathum, B.; Saikhun, K.; Sangsuwan, P.; Kitiyanant, Y. Effects of vitrification on nuclear maturation, ultrastructural changes and gene expression of canine oocytes. Reprod. Biol. Endocrinol. RbE 2010, 8, 70. [CrossRef] [PubMed] 
62. Yan, H.; Harding, J.J. Glycation-induced inactivation and loss of antigenicity of catalase and superoxide dismutase. Biochem. J. 1997, 328 (Pt 2), 599-605. [CrossRef]

63. Cebrian-Serrano, A.; Salvador, I.; Garcia-Rosello, E.; Pericuesta, E.; Perez-Cerezales, S.; Gutierrez-Adan, A.; Coy, P.; Silvestre, M.A. Effect of the bovine oviductal fluid on in vitro fertilization, development and gene expression of in vitro-produced bovine blastocysts. Reprod. Domest. Anim. Zuchthyg. 2013, 48, 331-338. [CrossRef] [PubMed]

64. Edashige, $\mathrm{K}$. The movement of water and cryoprotectants across the plasma membrane of mammalian oocytes and embryos and its relevance to vitrification. J. Reprod. Dev. 2016, 62, 317-321. [CrossRef] [PubMed]

65. Jablonski, E.M.; Mattocks, M.A.; Sokolov, E.; Koniaris, L.G.; Hughes, F.M., Jr.; Fausto, N.; Pierce, R.H.; McKillop, I.H. Decreased aquaporin expression leads to increased resistance to apoptosis in hepatocellular carcinoma. Cancer Lett. 2007, 250, 36-46. [CrossRef] [PubMed]

66. Yao, N.; Wan, P.C.; Hao, Z.D.; Gao, F.F.; Yang, L.; Cui, M.S.; Wu, Y.; Liu, J.H.; Liu, S.; Chen, H.; et al. Expression of interferon-tau mRNA in bovine embryos derived from different procedures. Reprod. Domest. Anim. Zuchthyg. 2009, 44, 132-139. [CrossRef]

67. Zhao, X.M.; Min, J.T.; Du, W.H.; Hao, H.S.; Liu, Y.; Qin, T.; Wang, D.; Zhu, H.B. Melatonin enhances the in vitro maturation and developmental potential of bovine oocytes denuded of the cumulus oophorus. Zygote 2015, 23, 525-536. [CrossRef]

68. Rizos, D.; Gutierrez-Adan, A.; Perez-Garnelo, S.; De La Fuente, J.; Boland, M.P.; Lonergan, P. Bovine embryo culture in the presence or absence of serum: Implications for blastocyst development, cryotolerance, and messenger RNA expression. Biol. Reprod. 2003, 68, 236-243. [CrossRef]

69. Gutierrez-Adan, A.; Rizos, D.; Fair, T.; Moreira, P.N.; Pintado, B.; de la Fuente, J.; Boland, M.P.; Lonergan, P. Effect of speed of development on mRNA expression pattern in early bovine embryos cultured in vivo or in vitro. Mol. Reprod. Dev. 2004, 68, 441-448. [CrossRef]

70. Rizos, D.; Ward, F.; Boland, M.P.; Lonergan, P. Effect of culture system on the yield and quality of bovine blastocysts as assessed by survival after vitrification. Theriogenology 2001, 56, 1-16. [CrossRef]

71. Arcarons, N.; Morato, R.; Spricigo, J.F.; Ferraz, M.A.; Mogas, T. Spindle configuration and developmental competence of in vitro-matured bovine oocytes exposed to $\mathrm{NaCl}$ or sucrose prior to Cryotop vitrification. Reprod. Fertil. Dev. 2015, 28, 1560-1569. [CrossRef] [PubMed]

72. Castillo-Martin, M.; Bonet, S.; Morato, R.; Yeste, M. Comparative effects of adding beta-mercaptoethanol or L-ascorbic acid to culture or vitrification-warming media on IVF porcine embryos. Reprod. Fertil. Dev. 2014, 26, 875-882. [CrossRef] [PubMed]

73. Rocha-Frigoni, N.A.; Leao, B.C.; Dall'Acqua, P.C.; Mingoti, G.Z. Improving the cytoplasmic maturation of bovine oocytes matured in vitro with intracellular and/or extracellular antioxidants is not associated with increased rates of embryo development. Theriogenology 2016, 86, 1897-1905. [CrossRef]

74. Esposti, M.D.; Hatzinisiriou, I.; McLennan, H.; Ralph, S. Bcl-2 and mitochondrial oxygen radicals. New approaches with reactive oxygen species-sensitive probes. J. Biol. Chem. 1999, 274, 29831-29837. [CrossRef]

75. Moawad, A.R.; Xu, B.; Tan, S.L.; Taketo, T. 1-carnitine supplementation during vitrification of mouse germinal vesicle stage-oocytes and their subsequent in vitro maturation improves meiotic spindle configuration and mitochondrial distribution in metaphase II oocytes. Hum. Reprod 2014, 29, 2256-2268. [CrossRef] [PubMed]

76. Schmittgen, T.D.; Livak, K.J. Analyzing real-time PCR data by the comparative C(T) method. Nat. Protoc. 2008, 3, 1101-1108. [CrossRef]

77. Livak, K.J.; Schmittgen, T.D. Analysis of relative gene expression data using real-time quantitative PCR and the 2(-Delta Delta C(T)) Method. Methods 2001, 25, 402-408. [CrossRef] [PubMed]

(C) 2020 by the authors. Licensee MDPI, Basel, Switzerland. This article is an open access article distributed under the terms and conditions of the Creative Commons Attribution (CC BY) license (http://creativecommons.org/licenses/by/4.0/). 